\title{
PERMEATION OF HELIUM INTO VACUUM
}

\section{TUBES}

by

John J. Rode

B.S., E.E. Kansas State College, 1949

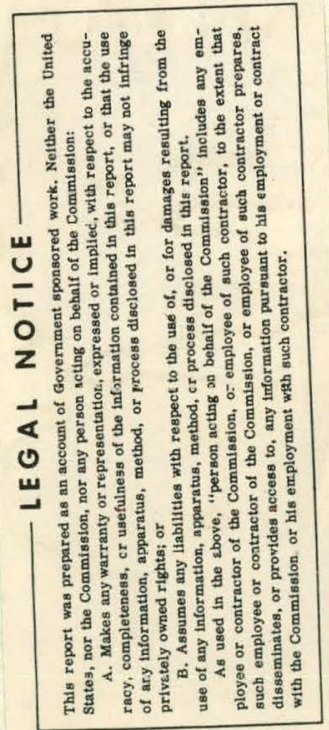

Submitted to the Department of Engineering and to the Faculty of the Graduate School of the University of Kansas in partial fulfillment of the requirements for the degree of Master of Science in Electrical Engineering. 


\section{DISCLAIMER}

This report was prepared as an account of work sponsored by an agency of the United States Government. Neither the United States Government nor any agency Thereof, nor any of their employees, makes any warranty, express or implied, or assumes any legal liability or responsibility for the accuracy, completeness, or usefulness of any information, apparatus, product, or process disclosed, or represents that its use would not infringe privately owned rights. Reference herein to any specific commercial product, process, or service by trade name, trademark, manufacturer, or otherwise does not necessarily constitute or imply its endorsement, recommendation, or favoring by the United States Government or any agency thereof. The views and opinions of authors expressed herein do not necessarily state or reflect those of the United States Government or any agency thereof. 


\section{DISCLAIMER}

Portions of this document may be illegible in electronic image products. Images are produced from the best available original document. 
THIS PAGE

\section{WAS INTENTIONALLY LEFT BLANK}




\section{ACKNOW LEDGMENTS}

The writer wishes to take this opportunity of expressing his appreciation to the many people who have contributed of their time and energy in the furtherance of this investigation. The writer is especially in debted to his advisor, R. D. Ellermeier; who has taken time from his own studies to provide a patient and helpful counsel. The many departments within The Bendix Corporation have by theix cooperation in providing laboratory space for over a year, preparation of graphs and photos, made a lighter task. The understanding and interest of the investigator's wife during this period is greatly appreciated.

J. J.R 


\begin{abstract}
Page

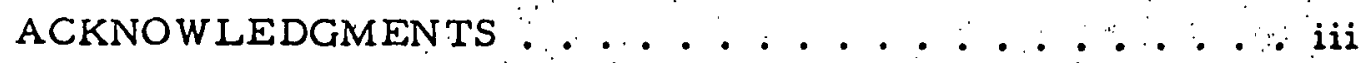

TABLE OF CONTENTS $\because \ldots . . . . . . . . . .$. iv

LIST OF TABLES ... . . . . . . . . . . v v

LIST OF FIGURES $. . . .^{\circ} . . . . . . . . . .$. vi

ABSTRACT .................. vii

CHAPTER
\end{abstract}

I. INTRODUCTION $\ldots . . . . . . . \cdots \cdot 1$

II. ANALYSIS OF GAS DIFFUSION $\quad \ldots \ldots \ldots 7$

III. EXPERIMENT NO. $1 \ldots . . . . . . .20$

IV. EXPERIMENT NO. 2 ........... 29

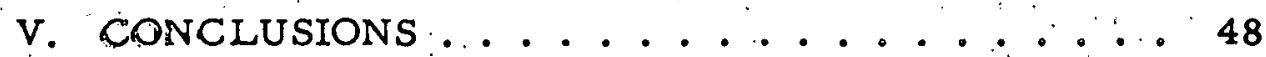

BIBLIOGRAPHY . . . . . . . . . . . . . 55

APPENDIX A Derivation of Fick's Equation.$\therefore \quad 58$

APPENDEX B: Solution of Fick's Equation . . . . . 65

APPENDIX C: Data Obtained for the Second Experiment. 70 
Table

1. Ion and Electron Current Readings

Taken During Experiment with 6 EN6's . . . $\because 70$

2. Experimental Results for Permeation Velocity, Solubility and Diffusion Coefficients Compared to Those Obtained by Norton and Altemose. . . . 46 


\section{LIST OF FIGURES}

Figure

Page

1. Glass Wall Thickness Determination ... ... . 22

2.: Grid Current Vs. Grid Voltage for 12AU7. ... . . 24

3. Internal Pressure Versus Days Immersed in Pure Helium Gas... . . . . . . . . . 26

4. Pressure Monitoring Circuit Using 12AU7 $\therefore 28$

5. Retarding Field Ionization Gauge Circuit for Monitoring Pressure Rise. . . . . . 30

6. Retar ding Field Ionization Gauge. ......... 31

7. Relative Internal Tube Pressure Vs Time...... 34

8. Relative Internal Tube Pressure Vs Time in Days . . 36

9. Relative Internal Pressure of Tubes Vs Time in Days 38

10. Hydrogen Thyratron Breakdown Voltage. .... 51

11. Power Output of Triode Oscillator Tube After Helium Immer sion ( $100 \% \mathrm{HE}, 2$ Atmo s.). ......... 52 


\section{ABSTRACT}

This thesis presents a mathematical analysis of the diffusion of helium gas through the glass walls of an evacuated $\left(10^{-8} \mathrm{~mm} \mathrm{Hg.}\right)$ electron tube. The analysis is based upon Fick's model of the diffusion in mechanism. The experimental measurements are accomplished by using the electron tube itself as a vacuum ionization gauge. The experimental results are in strong agreement with the developed theory. 


\section{INTRODUCTION}

Investigation into the effect of helium permeation of glass vacuum tube envelopes and its attendant effect on tube life was occasioned by previous investigations 1,2 aimed at determining the cause of erratic ignition of thyratrons which had been sealed in a helium atmosphere as well as determining the permeation effect on planar triodes. The permeation of helium into the hard vacuum tube is considered in this paper. A hard vacuum is a low pressure of approximately $1 \times 10^{-8} \mathrm{~mm}$. of $\mathrm{Hg}$. and the planar triode is of this type.

Purpose

The purpose of this paper is to extend previous investigations into the effect of helium permeation of glass vacuum tubes by providing an analytical foundation which defines the relationship between an external gas pressure and its time dependent effect on the internal pressure of a glass vacuum tube and to verify by experiment the predicted internal tube pressure rise as a result of diffusion through the glass envelope. Literature Research

The initial part of this investigation involved a detailed literature research to ascertain if there were any additional recorded instances where operation of vacuum tubes was adversely affected by permeation of a gas through their envelopes. Two sources were used, the Cumulative Book Index ${ }^{3}$ which is a listing of all technical books published by year and

Is. J. Catalano. Investigation of Helium Permeation into the Hydrogen Thyratron. (Unpublished) The Bendix Corp. K. C. D. 1960.

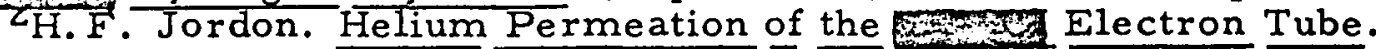
(Unpublished) The Bendix Corp. K.C.D. 1960

${ }^{3}$ Cumulative Book Index. The H. W. Wilson Company. 
by category and the Engineering Index ${ }^{4}$ which lists technical articles which have been published in professional society transactions, technical periodicals, company journals, etc:

Both the Cumulative Index and the Engineering Index are divided by categories under which are grouped all published information pertinent to the classification, the whole of which is grouped by the year. In order to reduce the chance of missing a reference due to its title causing it to be classified under an allied category, seventeen main categories were examined persistently as well as many others which provoked the least interest in their possibilities.

Six references were reviewed in detail because of the interest elicited by their titles and abstracts. None of the references yielded any information on the effects of gas permeation through the glass envelopes of vacuum tubes.

As a result of the literature research it should be noted that to list a complete bibliography on helium gas and its diffusion characteristics would be easy today, but due to the greater usage of helium atmospheres. and new applications it will be a difficult task in another decade. Circumstances Which Originated the Problem

The wide range of operating conditions encountered by missiles imposes the most severe environmental variations on electronic components, such as temperature sensitive resistors and capacitors, acceleration sensitive tube electrodes; and radiation sensitive dielectrics and semiconductors. Also, special dielectric designs are needed to confine and reduce corona in the vacuum of space.

${ }^{4}$ The Engineering Index, Engineering Index, Inc. New York. 
It is mecessary therefore to control or provide an artificial enviromment which will isolate the components from those extreme conditions which affect reliability by packaging the components in their own controlled environment. Reliability is affected by many factors; however, the most obvious and pertinent is environment, the aggregate of all the external conditions and influences affecting the operating life of the circuits.

Common solutions for controlling environment are encapsulation, hermetic sealing or a combination of both. The significant features of these two methods are:

A. Encapsulation provides good isolation from moisture and gives mechanical constraint to individual components which is advantageous in enduring shock and vibration environments. Generally, however, encapsulants are poor thermal conductors and provide servicing problems in component replacement.

B. Hermetic sealing with a chemically inert, dry gas, at a pressure representing a normal atmosphere provides moisture isolation and relatively constant pressure in any environment. This technique allows replacement of components within sub-" assemblies without the necessity of scrapping expensive units as would be the case for an encapsulated subassembly. As practiced, hermetic sealing involves sealing the circuits in: an environment of helium gas with a positive pressure. In case of leakage, the container would leak outward, preventing the ingress of moisture laden air.

The quality of a hermetic seal is specified in terms of allowable: leakage rate. For those items which may be unattended for years the 
leakage rates are necessarily stringent and are usually given in standard $\mathrm{cc} / \mathrm{sec}$ or the larger units of micron-ft ${ }^{3} / \mathrm{hr}$. The units are based on a standard atmosphere $(760 \mathrm{~mm} \mathrm{Hg.} \mathrm{)} \mathrm{differential.}$

Further discussion is limited to the case of hermetic sealing since the environment provided by the hermetic package originated the problem covered by this paper.

Use of Helium

To insure the quality of hermetic electronic packages and the satisfaction of contractual specification requirements, an inert gas is introduced into the evacuated as sembly and sealed off by normal means such as "O!" ring seals. The complete hermetically sealed container is then placed into a chamber which is evacuated to a pressure of one micron or less. Connected to the chamber is a mass spectrometer sensitive to the fill gas. Any fill gas leaking out would be detected by the mass spectrometer and its leak rate measured by comparison to calibrated leak rate standards.

The most favored gas is helium; it is chemically inert, noninflammable, and exists in low concentrations in the normal atmosphere: As a consequence of its low mass and small molecular diameter, helium exhibits a diffusion capability of 2.6 times that of air. This relative diffusion factor is obtained by taking the ratio of the square root of the molecular weight of air, 28.7, to the square root of the molecular weight of helium, 4.00. The high diffusivity of helium over air gives it an advantage in passing through molecular sized apertures. It is because of this property that helium gas is used to check tightness of enclosures

${ }^{5}$ A Guthrie and R. Wakerling. Vacuum Equipment and Techniques. McGraw-Hill, 1949 p8. 
which are required to be hermetic; viz. relay cans, "dry" switch contacts and mechanical assemblies which are to operate in a dust and moisture free environment. It followed naturally that helium would be used in permeation studies wherever the leak rate requirements were sufficiently low that the mass spectrometer technique could be used. Since this equipment was readily available it was economically wise to utilize the same instrumentation for all leak rate measurements.

Workers in hermetic sealing learned of the permeation ability of helium through experience obtained from the large amount of rework necessary in achieving "tight"' seals. Many of these workers, not well acquainted with its physical characteristics, were relating the permeation of helium to its ability to flow through metal. No consideration was given to the permeability of glass to helium when electronic circuits containing glass vacuum tubes were stored in hermetic containers under a pure helium gas pressure of several atmospheres.

However, experimental measurements of the permeation of gas through glass are quite old and the significance of this type of permeation is now generally recognized. The permeation of glass by various gases has been measured experimentally over the past fifty years for a wide variety of glasses. In 1924, C. C. van Voorhis reported a study in which attention was centered on the relation of permeability to chemical composition of the glass. His work appears to be the beginning of a series of similar investigations aimed at the understanding of the fundamental physical and chemical factors influencing permeation. 6

6W. Rogers, R. Buritz and D. Alpert. Diffusion Coefficient, Sululility, and Pcrmeability for Helium in Glass. Journal of Applied Physics. VZ5, N7 July 1954 
Succeeding chapters will develop a unique method for both theoretical and experimental analysis of the effect of helium permeation through sealed vacuum tube envelopes where the use of mass spectrometry is impractical because it results in the destruction of the test sample in order to connect the spectrometer. 


\section{ANALYSIS OF GAS DIFFUSION}

The quantitative analysis of gas diffusing through a permeable membrane is best introduced by the second order differential associated with the Fick Law: "The rate of diffusion of particles across a given area is proportional in amount and opposite in sign to the concentration gradient. "l For diffusion in solids, a phenomenon which occurs slowly, three processes may be responsible; ${ }^{2}$ (a) direct exchange of atoms on the sites involved, (b) migration of interstitial atoms, e.g., an atom squeezed between the regular lattice sites in a crystal, and (c) diffusion of vacancles. A vacancy is described as a site in the crystal lattice. of an lonic crystal from which the ion which should be present is missing. From the Kirkendall ${ }^{3}$ Effect it appears that (b) and (c) are the usual processes and in the case covered by this paper, (b) applies although it is later shown that glass is not a crystal. The Kirkendall Effect is demonstrated by placing markers at the interface between an alloy $(\mathrm{Cu}$ $\left.Z_{n}\right)$ and a metal $(\mathrm{Cu})$, and the whole heated to a temperature where diffusion is possible. When this temperature is reached the markexs move towards the allny region. This is explained by as suming that the zinc diffuses more rapidly than the copper, and thus diffuses out of the alloy. Such a process is impossible if the diffusion is by direct exchange of atoms.

${ }^{1}$ D. Van Nostrand Co. The International Dictionary of Physics and Electronics 1956. Page 238

Tbia., p. 239

$3 \overline{\mathrm{Ib}} \overline{\mathrm{id}} ;$ p. 490 
Gas diffusion was first put on a quantitative basis by Fick who adapted the mathematical equation of heat conduction derived by Fourier. A clearer connection between heat flow and gas diffusion can be made if one follows the derivation of Fick's Law ${ }^{4}$ in terms of gas concentration. Cylindrical Solution

Two approaches were considered in analyzing the diffusion of a : gas through the glass envelope of a vacuum tube. The first was. to consider the glass as a right circular cylinder, assuming the irregular ends to be planar. This treatment requires'the three dimensional solution of Flck's Law in terms of cylindrical coordinates:

$$
\frac{\partial c}{\partial t}=D\left[\frac{\partial^{2} c}{\partial r^{2}}+\frac{1}{r} \frac{\partial c}{\partial r}+\frac{1}{r^{2}} \frac{\partial^{2} c}{\partial \theta^{2}}+\frac{\partial^{2} c}{\partial z^{2}}\right],
$$

where $c$ is the gas concentration, $t$ is time, $D$ is diffusion constant and $r, \theta$ and $Z$ are parameters of the cylindrical coordinate system. Equation (1) may be simplified by the observation that the diffusion of gas is not a function of either the $\theta$ or $z$ parameters and thus reduces to

$$
\frac{\partial c}{\partial t}=D\left[\frac{\partial^{2} c}{\partial r^{2}}+\frac{1}{r} \frac{\partial c}{\partial r}\right]
$$

With the application of appropriate boundary limits and initial conditions and proper selection of cylindrical functions the three dimensional solution can be found; however, this method was considered a disadvantage because of the tediousness in working in three dimensions and the comparable accuracy achieved by a more approximate solution using a rectangular coordinate system.

${ }^{4}$ Appendix A 
Rectangular Solution

The second approach, which was used, was to assume that the right circular cylinder could be split and rolled out into a flat sheet, this only requiring the use of a two coordinate rectangular system. The glass envelope was assumed to be a thin membrane of thickness $d$ with a gas concentration $c_{2}$ on the inside of the tube with a volume $v_{1}$ and a concentration $c_{1}$ on the outside. Fick's equation in terms of two variables was then

$$
\frac{\partial c}{\partial t}=D \frac{\partial^{2} c}{\partial x^{2}}
$$

Membrane thickness is $x ; t, c$, and $D$ as in Equation (1). To determine the solution of Equation (3) it was necessary to apply boundary conditions and initial conditions which were as near as practicable to conditions encountered in the experiment. Using the simplified approach, a solution to Fick's equation is then directly obtainable in order to explain the mechanism of helium diffusion.

Consider a cross section of the blass membrane as shown in Figure 1.

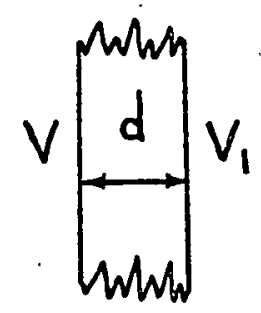

Figure 1. Membrane Cross Section

The proposed experimental conditions were to assume initially that the gas concentration in the tube volume $V_{l}$, was zero; the gas concentration outside the membrane would be zero initially and at time $t=0$ a given concentration would be present. Also, the initial concentration within the membrane would be zero. 
- To provide a more general solution which would be applicable to other conditions which might have been imposed the following conditions were chosen:

$$
\begin{aligned}
\text { At } t & =0, c=f(x) \text { for } 0<x<d \\
t & >0, c=c_{1} \text { for } x=0 \\
t & >0, c=c_{2} \text { for } x=d
\end{aligned}
$$

The solution was then determined ${ }^{5}$ as

$$
\begin{aligned}
& c(x, t)=\left(c_{2}-c_{1}\right) \frac{x}{d}+c_{1}+\frac{2}{d} \sum_{1}^{\infty} e^{\frac{-n^{2} \pi^{2} t D}{d t}} \sin \frac{n \pi x}{d} \int_{0}^{d} f(x) \sin \frac{n \pi x d x}{d} t \\
& \frac{2}{\pi} \sum_{1}^{\infty} \frac{c_{2} \cos n \pi-c_{1}}{n} \sin \frac{n \pi x}{d} e^{\frac{-n^{2} \pi^{2} t D}{d^{2}}}
\end{aligned}
$$

The equation is a general one giving the concentration of gas in the membrane at any time and fulfilling the requirements imposed by the boundary conditions.

The expression in (4) simplifies under the conditions proposed for the experiment where the membrane is assumed initially devoid of gas, or $c=f(x)=0$.

Generally the concentration $c$ is not known but the pressure on the surface of the membrane is known. The concentration $c$ of dissolved gas is then expressed as the pressure of the same concentration of gas in the free state at the standard temperature $\left(0^{\circ} \mathrm{C}\right)$. It is necessary therefore to relate the pressure $p_{1}$ and $p_{2}$ to the boundary values of the concentration $c$ at the surface.

Considering the conditions applicable to the experiment where there is an internal volume $V 1$ separated from an external volume $V$ by a glass membrane, it is assumed that both volumes and membrane are 
initially devoid of the gas, helium. It might be argued that, as a result of the normal concentration of helium in the atmosphere, a permeable membrane which essentially is exposed to one atmosphere pressure differential would absorb some helium.

It has been shown ${ }^{6}$ that the most reliable absolute value of the helium content of ground level air is $5.239 \pm 0.004$ parts per million. The total gas pressure of the atmosphere is the sum of the partial pressures of each constituent gas. Therefore, with the concentration of helium given, that partial pressure which may be ascribed to helium is only 3.98 microns.

The partial pressure of helium in $V$ compared to the internal pressure in $\mathrm{V}_{1}$ is essentially zero under the experimental conditions imposed. The validity of this assumption is realized when the glas is subjected to several atmospheres of pure helium gas. This is explained by comparing the internal pressure of a hard vacuum tube $\left(1 \times 10^{-8} \mathrm{~mm}\right.$ of $\mathrm{Hg.)}$ with the applied external pressure $(380 \mathrm{~cm}$ of $\mathrm{Hg}$.). If the internal pressure of a vacuum tube is $1 \times 10^{-8} \mathrm{~mm}$ of $\mathrm{Hg}$., the applied external helium pressure is $3.8 \times 10^{-3} \mathrm{~mm}$ of $\mathrm{Hg}$, and the normal partial pressure is $3.98 \times 10^{-3} \mathrm{~mm}$ of $\mathrm{Hg}$, , then the as sumption that the membrane has been exposed to zero pressure helium is explained by the relationship

$$
\frac{3.98 \times 10^{-3}}{1 \times 10^{-8}} \ll \frac{3.8 \times 10^{3}}{1 \times 10^{-8}}
$$

The diffusion coefficient $D$ is defined as the rate of transfer of the diffusing substance across a unit area of section divided by the space gradient of concentration at the section. If the rate of transfer is $F, c$

6E. Gluckauf. Proceedings Royal Society, Al85, 98 (1946) 
is the concentration of the diffusing substance, and $x$ is the space coordinate normal to the section, then?

$$
F=-D \frac{\partial c}{\partial x}
$$

In examining the diffusion factor, $D$, it is necessary to ascertain its linearity or non-linearity when applied to the membraneous material, glass. If $D$ is linear, i.e., exhibits the same value in the $x, y$, or $z$ direction within an isotropic material, it can be considered a constant for a given isotropic medium and must thus be considered in the solution of Fick's Equation. The diffusion coefficient $D$ exhibits non-linearity in a crystalline structure or any non-isotropic medium, either metallic or ionic. This type of diffusion is said to be structure sensitive. ${ }^{8}$

Glass, being the material under discussion, is considered a noncrystalline isotropic medium by Kohl who says:

"In the case of a glass-forming compound the transition from the liquid to the solid phase is not sharply defined.... While there is a narrow range of temperature where a tendency towards crystallization (devitrification) exists, this range is passed quickly enough during the cooling of the glass melt so that the rapidly increasing viscosity of the melt freezes the molecular aggregates as they exist in the liquid state and maintains the disorderly array at room temperature where glass is a rigid body. "19

Warren and Biscoe also agree: "Although it is a perfectly definite scheme of structure there is no regular repetition in the pattern, and

\footnotetext{
7 J. Crank. Mathematics of Diffusion. Oxford 1956

${ }^{8}$ R. M. Barrer. Diffusion In and Through Solids. Cambridge, 1951

${ }^{9}$ W. H. Kohl. Materials Technology for Electron Tubes. Reinhold Pub.
} 
hence the structure is noncrystalline. 110

From the forgoing then, the difference between a crystalline solid and a vitreous body, such as glass, is a matter of the size of the regions through which molecular aggregates of definite structure extend. Diffusivity is therefore considered constant for the glass membrane. If the diffusion coefficient $D$ is constant, and if the sorption isotherm is linear, i.e., if there is a linear relationship betwe en the external vapor pressure and the corresponding equilibrium concentration within the membrane, then

$$
F=-D \frac{d c}{d x}=D \frac{\left(c_{2}-c_{1}\right)}{d}
$$

where $F$ is the transfer rate, $c_{1}$ and $c_{2}$ the concentration on either side of the membrane of thickness $d, D$ as previously defined, and $c$ is the concentration within the membrane. This is equivalent to

$$
F=P \frac{\left(p_{2}-p_{1}\right)}{d}
$$

where $P$ is the permeation constant and $p_{1}, p_{2}$, are boundary value pressure related to $c_{1}$ and $c_{2}$ through

$$
c_{n}=S_{p n}
$$

where S, solubility, is the dimensionless ratio of concentration of solute inside the glass to that outside the glass. Concentration $c$ and pressure $p$ have previously been defined. The subscript $(n)$ is an identification integer.

${ }^{10}$ B. E. Warren and J. Biscoe. Fourier Analysis of X-Ray Patterns of Soda-Silica Glass. J. Am. Ceram-Soc. $21, \overline{1} \overline{938.0}$. 
A relationship between $c$ ard $p$ may be obtained from Equation (6) and (7) as

$$
P\left(\frac{\left.p_{2}-p_{1}\right)}{d}=D \frac{\left(c_{2}-c_{1}\right)}{d}=F\right.
$$

With a linear isotherm, Equation (8) holds, where again, $c$ is the concentration within the membrane, $\mathrm{p}$ is the external pressure and $\mathrm{S}$ is the solubility.

With the two preceding relationships established and with the proper regard to units:

$$
P=D S
$$

In consideration of dimensions; solubility is dimensionless; therefore, permeability, which is given in cubic centimeters at N.T.P. / second/ $\mathrm{cm}^{2}$ area/mm thickness of material/cm Hg. pressure difference, has the same dimensions as the diffusion rate.

Referring back to the experimental initial conditions where it was assumed that the glass membrane was initially devoid of gas (or $c=f(x)=0$ ); substitution in (4) yields a simpler solution

$$
c(x, t)=\left(c_{2}-c_{1}\right) \frac{x}{d}+c_{1}+\frac{2}{\pi} \sum_{n=1}^{\infty} \frac{c_{2} \cos n \pi-c_{1}}{n} \sin \frac{n \pi x}{d} e^{\frac{-n^{2} \pi^{2} t D}{d^{2}}}
$$

As is described above, the concentration c does not achieve a uniform value throughout the glass. Since the transfer of gas particles between the surface layer and the free state in the adjacent volume $V_{1}$ is very rapid in comparison with the diffusion through glass, it is reasonable to as sume that the equilibrium value of $c$ is immediately established at the boundary. 
To determine the pressure buildup in the tube volume the current density of the gas diffusing through the total area of the glass membrane into the volume will have to be evaluated at the boundary of the membrane and internal volume. The rate of flow was previously given as: $-D\left(\frac{\partial c}{\partial x}\right)$ The flow of gas throughan area $A$ into a volume $V I$ is then

$$
V_{1}: \frac{\partial C_{g}}{\partial t}=-A D\left(\frac{\partial c}{\partial x}\right)
$$

or

$$
\frac{\partial C g}{\partial t}=-\frac{A D}{V_{1}}\left(\frac{\partial c}{\partial x}\right) x=d
$$

From the previous solution given in (II) and, taking the partial differential;

$\left(\frac{\partial c}{\partial x}\right)=\frac{c_{2}-c_{1}}{d}+2 \sum_{n=1}^{\infty} \frac{1}{d}\left(c_{2} \cos n \pi-c\right) \cos \frac{\cos \pi x}{d} e^{\frac{-n^{2} \pi^{2} t D}{d^{2}}}$

Rearranging and evaluating at the boundary $x=d$ :

$$
\left(\frac{\partial c}{\partial x}\right)_{x=d}=\frac{c_{2}-c_{1}}{d}+\frac{2}{d} \sum_{n=1}^{\infty}\left(c_{2} \cos n \pi-c_{1}\right) e^{\frac{-n^{2} \pi^{2} t D}{d^{2}}}
$$

Sosbituting (15) in (13):

$$
\frac{\partial C_{g}}{\partial t}=-\frac{A D}{V_{1}}\left[\frac{c_{2}-c_{1}}{d}+\frac{2}{d} \sum_{n=1}^{\infty}\left(c_{2} \cos n \pi-c_{1}\right) e^{\frac{-n^{2} \pi^{2} t D}{d^{2}}}\right]
$$

where $C_{g}$ denotes the concentration of the gas which has diffused through the glass membrane into the volume at a time $t$. The condition that $c=c_{2}$ at $x=d$ for all $t$ naturally makes it necessary that $C g \ll c_{2}$.

Therefore the quantity; $Q$, of gas which has diffused in time $t$ is given by 


$$
Q=-\int_{0}^{t} D\left(\frac{\partial c}{\partial x}\right) \frac{d t}{x=d}
$$

Then from (17), on completing the integration and substituting in the limits:

$$
\text { Qor } C_{g}=\frac{A D}{V_{1} d}\left(c_{2}-c_{1}\right) t+\frac{2 A d}{V_{1} \pi^{2}} \sum_{n=1}^{\infty} \frac{\left(c_{2} \cos n \pi-c_{1}\right)}{n^{2}}\left(1-e^{\frac{-n^{2} \pi^{2} t D}{d^{3}}}\right)
$$

Consider the series after the summation sign as $t$ becomes large or $t$ 00; this expression will become

$$
\sum_{n=1}^{\infty} \frac{\left(c_{2} \cos n \pi-c_{1}\right)}{n^{2}}\left(1-e^{\frac{-n^{2} \pi^{2} t D}{d^{2}}}\right)=\sum_{n=1}^{\infty} \frac{c_{2} \cos n \pi-c_{1}}{n^{2}}
$$

In order to evaluate this series, the expression can be represented as a sum of two series:

$$
\sum_{n=1}^{\infty}\left[c_{2}\left(\frac{1}{n^{2}} \cos n \pi\right)+c_{1}\left(-\frac{1}{n^{2}}\right)\right]
$$

It has been shown ${ }^{11}$ that $\frac{1}{n} z^{\cos n}$ may be regarded as a Fourler series representation of the function

$$
\frac{\pi^{2}}{4}\left[(1-x)^{2}-\frac{1}{3}\right] \text { for } 0<x \leq 1 \text { evaluated at } x=1
$$

and similarly the term $\frac{(-1)}{n} \frac{1}{2}$ may also be regarded as a half-range Fourier. series representation of the function $\frac{\pi^{2}}{2}\left[(1-x)^{2}-\frac{1}{3}\right]$ with the same conditions imposed on $x$.

Equation (18) can now be written:

${ }^{11}$ T. Holstein. Westinghouse Research Report 411-9-D 


$$
C_{g}=\frac{A D}{V_{1} d}\left(c_{2}-c_{1}\right) t+\frac{2 A D}{V_{1} \pi^{2}}\left[c_{2} \frac{\pi^{2}}{4}\left(-\frac{1}{3}\right)+c_{1} \frac{\pi^{2}}{2}\left(-\frac{1}{3}\right)\right],
$$

or

$$
C_{g}=\frac{A D}{V_{1} d}\left[\left(c_{2}-c_{1}\right) t-\frac{c_{2} d^{2}}{6 D}-\frac{c_{1} d^{2}}{3 D}\right]
$$

With Equation (8) substituted in order to provide a more practical equation:

$$
P_{g}=\frac{A D S}{V_{1} d}\left[\left(p_{2}-p_{1}\right) t-\frac{p_{2} d^{2}}{6 D}-\frac{p_{1} d^{2}}{3 D}\right]
$$

where $\mathrm{P}_{\mathrm{g}}$ is the internal gas pressure.

If under the boundary conditions established, there were no time lag, $P g$ would be expressed by $P_{g}=\frac{A D S}{V_{1} d}\left(p_{2}-p_{1}\right) t$. If $p_{1} \approx 0$, which is the experimental case, then

$$
P_{g}=\frac{A D S}{V_{1} d} p_{2} t
$$

Since there is a time lag, it is possible to determine the intercept (L) of the straight line portion of a plot of $p$ versus $t$ at the time axis from Equation (23).

Examination of Equation (23) shows, that for small values of $t$, the sum of the negative terms, $-\frac{p_{2} d^{2}}{6 D}-\frac{p_{1} d^{2}}{3 D}$, will exceed the value of the positive term, $\left(p_{2}-p_{1}\right) t$, and result in a negative internal tube pressure $P_{G}$. A negative pressure is an impossibility, therefore the value of $t$ required to cause $\mathrm{Pg}=0$, is given as $t_{c}$ or the intercept $L$ on the time axis. The value of $L$ is determined from the following or at $p_{1}=0$, the 
18

value of ADS only determines the slope and since only an intersection $\nabla \bar{l} \bar{d}$

point is wanted:

$$
\begin{aligned}
& p_{2} t_{c}-\frac{p_{2} d^{2}}{6 D}=0 \\
& t_{c} \text { or } L=\frac{p_{2} d^{2}}{p_{2} 6 D} \\
& t_{c}=\frac{d^{2}}{6 D}
\end{aligned}
$$

It is obvious that if the straight portion of the curve is extended to the time axis, the value of $t_{c}$ obtained can be used in obtaining the diffusion coefficient, $D$, since

$$
D=\frac{d^{2}}{6 t c}
$$

Similarly, solubility $S$ may be determined from the time lag equation as shown;

$$
P_{g}=\frac{A D S}{V_{1} d} P_{2}\left(t-\frac{d^{2}}{6 D}\right)
$$

or, rearranging,

$$
S t-\frac{S d^{2}}{6 D}=\frac{P_{g} V_{1} d}{A \cdot D_{p_{2}}}
$$

When $t=0$ the pressure axis intercept is

$$
S=\frac{-6 V_{1} P_{g}}{A d p_{2}}
$$

If it were assumed that the diffusion coefficient $D$ was of the order of $7 \times 10^{-9} \mathrm{~cm}^{2} / \mathrm{sec}$ then the length of time for helium to diffuse through a membrane $0.08 \mathrm{~cm}$ thick and reach a constant rate would be

$$
t_{c}=\frac{d^{2}}{6 D}=1.52 \times 10^{-5} \text { seconds }
$$

(30) 
or approximately two days to establish a linear change with time in the internal pressure.

In those cases where there is an initial pressure in the membrane under consideration, then steady-state conditions, or as $t \rightarrow \infty$, the accumulated concentration of gas would be ${ }^{12}$

$$
C_{g}=\frac{D}{d V_{1}}\left[\left(c_{2}-c_{1}\right) t-\frac{c_{2} d^{2}}{6 D}-\frac{c_{1} d^{2}}{3 D}+\frac{c_{0} d^{2}}{2 D}\right]
$$

where $c_{0}$ i.s the initial concentration in the membrane.

It can be seen that (31) is similar to (22) except for the term representing the initial membrane gas concentration, $\frac{c_{0} d^{2}}{2 D}$ however, under the boundary conditions established for the experiment, the Initial concentration in the membrane was assumed equal to zero. It has been shown that the quantity of gas diffusing through a membrane per unit time is proportional to the area of the membrane, the pressure gradient across the membrane, and the diffusion constant of the membrane and inversely proportional to the membrane thickness and volume into which the gas is diffusing.

In the succeeding chapters which deacribe the experiment, the equations involving $D, S$ and $P$ will be utilized in a stmplified method for measuring the permeation rate of helium.

12 R. M. Barser. op. cit. 


\section{CHAPTER III}

\section{EXPERIMENT \#I}

By relating the theoretical relationships of helium permeation, diffusion constant, membrane thickness and pressure gradient to a practical problem, it is possible to affirm the predicted permeation behavior with a minimum of precision instrumentation as is described in the experiments.

Two experiments were performed to verify the permeation properties of helium. The first experiment was discontinued after 71 days and considered a failure because, the data was inconclusive. Verification of the analytical proof is supplied by the results of the second experiment. Each experiment is described; however, the details of the first and discontinued experiment are not delved into as much as the second effort.

The gas pressure in a vacuum tube can be detected by utilizing the tube itself as an ionization gauge. The pressure builds up as a result of helium permeating from the high pressure outside of the glass envelope to the low pressure inside of the tube and can be detected by an increase in the ion current. This ion current bears the relationship to the internal pressure p;

$$
\frac{I t}{I-}=k p
$$

The ionization current is the positive ion current, It, caused by the electron current I- colliding with gas molecules. The gauge constant, $k$ is complex and truly not constant but dependent on pressure and electron emmission current I- as well as the type of gas being measured which involves ionization efficiency. Ionization efficiency, is generally an experimentally determined number dependent only on the electron energy for a 
particular gas. The typical value for nitrogen is 11 at 100 volts. 1 This number means, according to Nottingham and Torney, "that on the average, a 100 volt electron travelling through nitrogen at I millimeter pressure and at $0^{\circ} \mathrm{C}$ will produce an ion in a distance of $(1 / 11) \mathrm{cm}$. The concentration of nitrogen atoms under this standard condition is $3.54 \mathrm{x}$ $10^{16}$ atoms per.cc."2 For example, the ratio of the ionization efficiency of nitrogen to helium has been determined by Compton and Van Voorhis ${ }^{3}$ for an electron energy of 50 volts to be approximately 9 . In the practical ionization gauge, not all of the electron emission current is effective in producing ionization and not all of the ions produced are collected.

A double triode tube, type 12AU7, was arbitrarily chosen in the first experiment. It was electrically operated with like electrodes paralleled. The glass area was calculated assuming that the tube was a right circular cylinder; internal volume was determined by the water method and the average glass thickness determined by radiographic meas-: urement. Figure I shows two radiographed views of the tube, one view is with the tube rotated $90^{\circ}$. The estimated maximum error of measurement by this method is $12 \%$. The glass is Corning 0080, a Soda-lime glass. 4

Two approaches were used to detect ion production. The first method operated the anode or plate at a negative potential with respect to the cathode, and the grid positive with respect to the cathode. Results

\footnotetext{
. $1_{K}$. T. Compton and C. C. Van Voorhis. Physics Review V27, 724(1962)

${ }^{2}$. B. Nottingham and F. L. Torney, Jr. A Detailed Examination of the Principles of Ion Gauge Calibration. American Vacuum Society, Seventh National Symposium.

3 Compton and Van Voorhis. op. cit.

${ }^{4}$ Correspondence - Sylvania Electric Products Inc., April 13, 1962.
} 
FIGURE I

\section{GLASS WALL THICKNESS DETERMINATION}

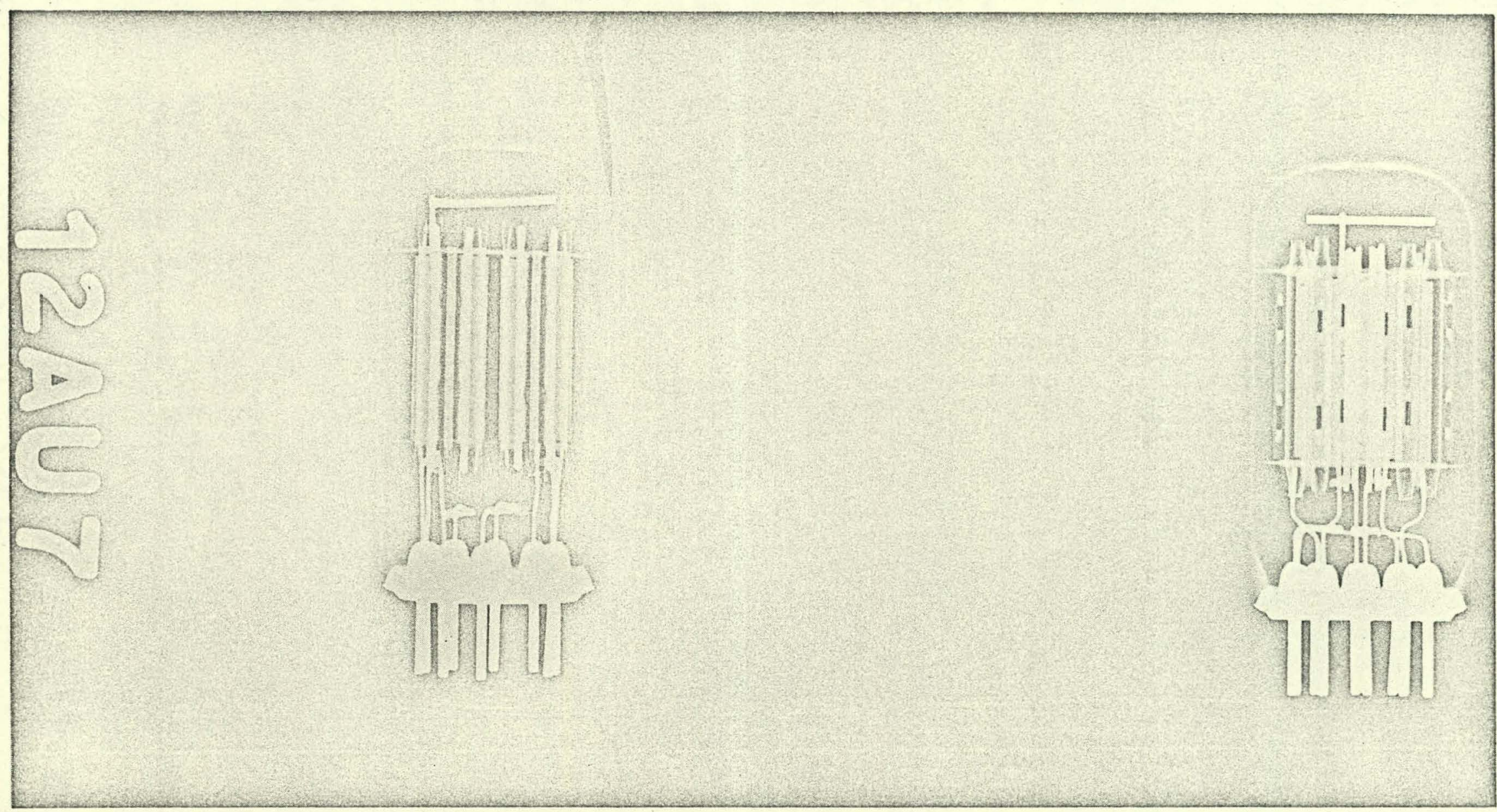


were unsatisfactory because the small positive ion current detected in the anode circuit was masked by dielectric leakage current of the porcelain tube socket and associated wiring. Resistance of the tube socket and external wiring measured $1 \times 10^{12}$ ohms. With the tube operating in its socket the resistance decreased to $9 \times 10^{10}$ ohms. Detected positive ion current measured in the range of $10^{-10}$ amperes. High grid current, 20 milliamperes, was necessary to produce ions in the small sampling volume of the tube; however, this opposed the philosophy of maintaining low electron current emission to limit X-radia-. tion and secondary emission effects. Accuracy of an ionization gauge is reduced by excessive electron emission current and since high electron current is usually produced by high electrode potentials, X-radiation and photon emission caused by this combination of current and voltage will produce ions in unpredictable quantities and destroy the idealistic linear relationship between electron emisssion current and ion current.

The second method for detecting ionized gas particles utilized a positive anode voltage of 50 volts. The negative grid potential was chosen down on the grid voltage-grid current curve. A typical curve for this tube type is hown in Figure 2. Two voltage points were chosen, -2.0 and -3.2 volts which gave electron emission currents of about 3 and 1 milliamperes respectively. Operating on the gentler slope of the curve imposed a less severe stability requirement on the grid bias power supply and provided better repeatability in the data. Operation on the negative peak of the grid voltage-grid current curve provides the most copious quantities of positive ions but the low negative bias allows excessive electron curxent to flow, rapidly heating the tube and causing 
FIGURE 2

\section{GRID CURRENT VS. GRID VOLTAGE FOR 12 AU7}

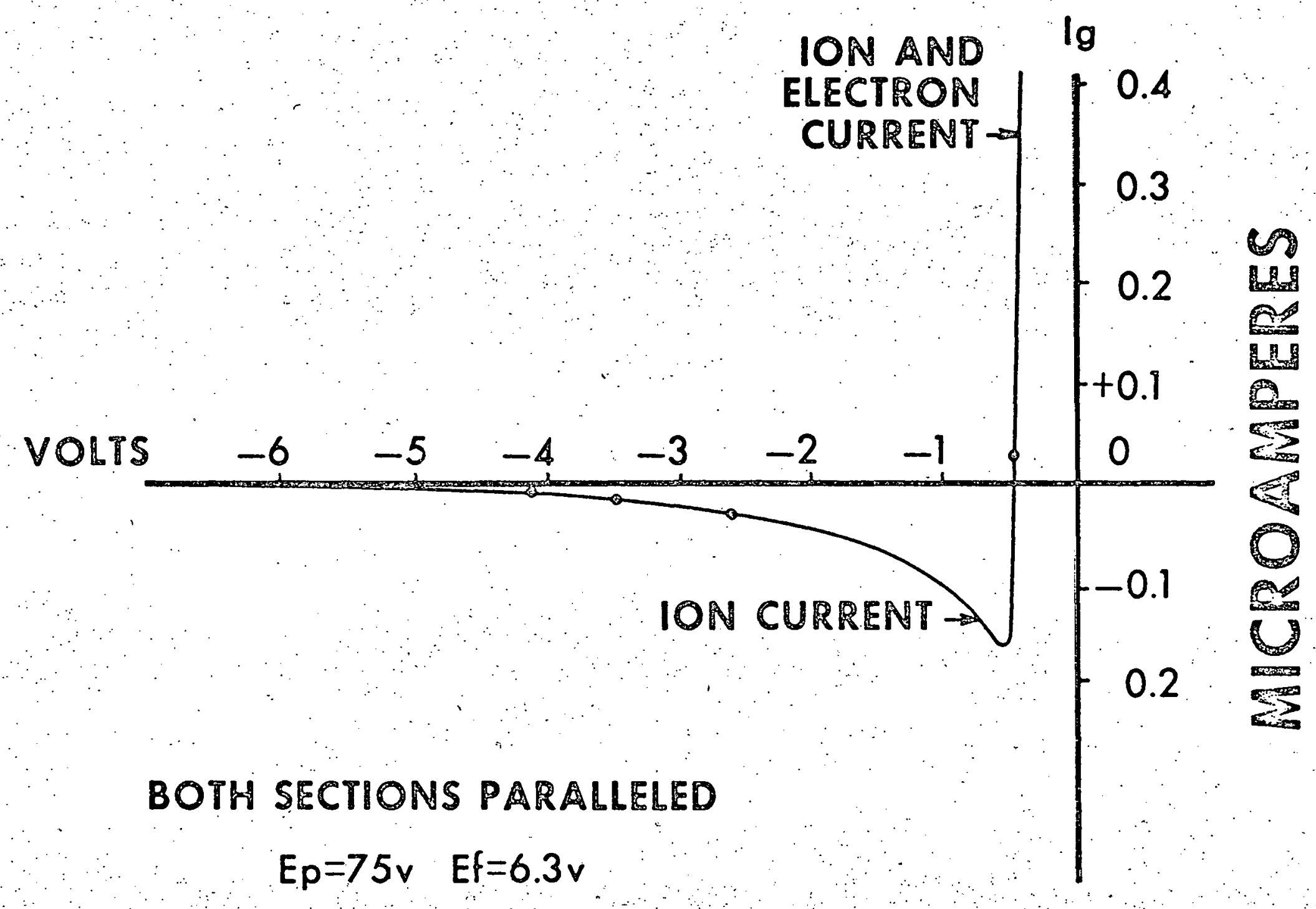


unstable readings.

The test program involving the first experiment and utilized with few alterations in the second was this: Six vacuum tubes were split into a control group and a test sample group. The tubes in the test sample group were inserted in a metal container which could be sealed off, evacuated of air and then pressurized with pure helium gas. Immersed tubes are frequently referred to in the following discussions as "soaked" tubes. At intervals these tubes were removed, inserted in the measuring circuit and their electron and ion currents measured with always the same electrode voltages applied. The control tubes which were stored in normal atmospheric pressure and temperature were also measured for comparison with the tubes which were being soaked in helium. After the readings were taken the test sample tubes were returned to their environment of pure helium. It was predicted by Equation 23, Chapter II, that after a short time interval the soaked tubes should show a gradual and continuing increase in ion current compared to the control tubes, indicating that the internal tube pressure was rising due to permeation of: helium through the glass envelope.

In Figure 3 are the results for five 12 AUT tubes immersed for 71 days in an atmosphere of pure helium at a pressure of 1 atmosphere absolute for 30 days. At the thirtieth day the external helium pressure was doubled and remained at that pressure until the experiment was terminated.

Examination of the curves for the relative pressure of the five tubes illustrates the rcason for discontinuing the measurements. The apparent randomness and lack of any discernible trend are evident. Two. reasons are advancc'd for the failure of this experiment: 
FIGURE 3

INTERNAL PRESSURE VERSUS DAYS IMMERSED IN PURE HELIUM GAS

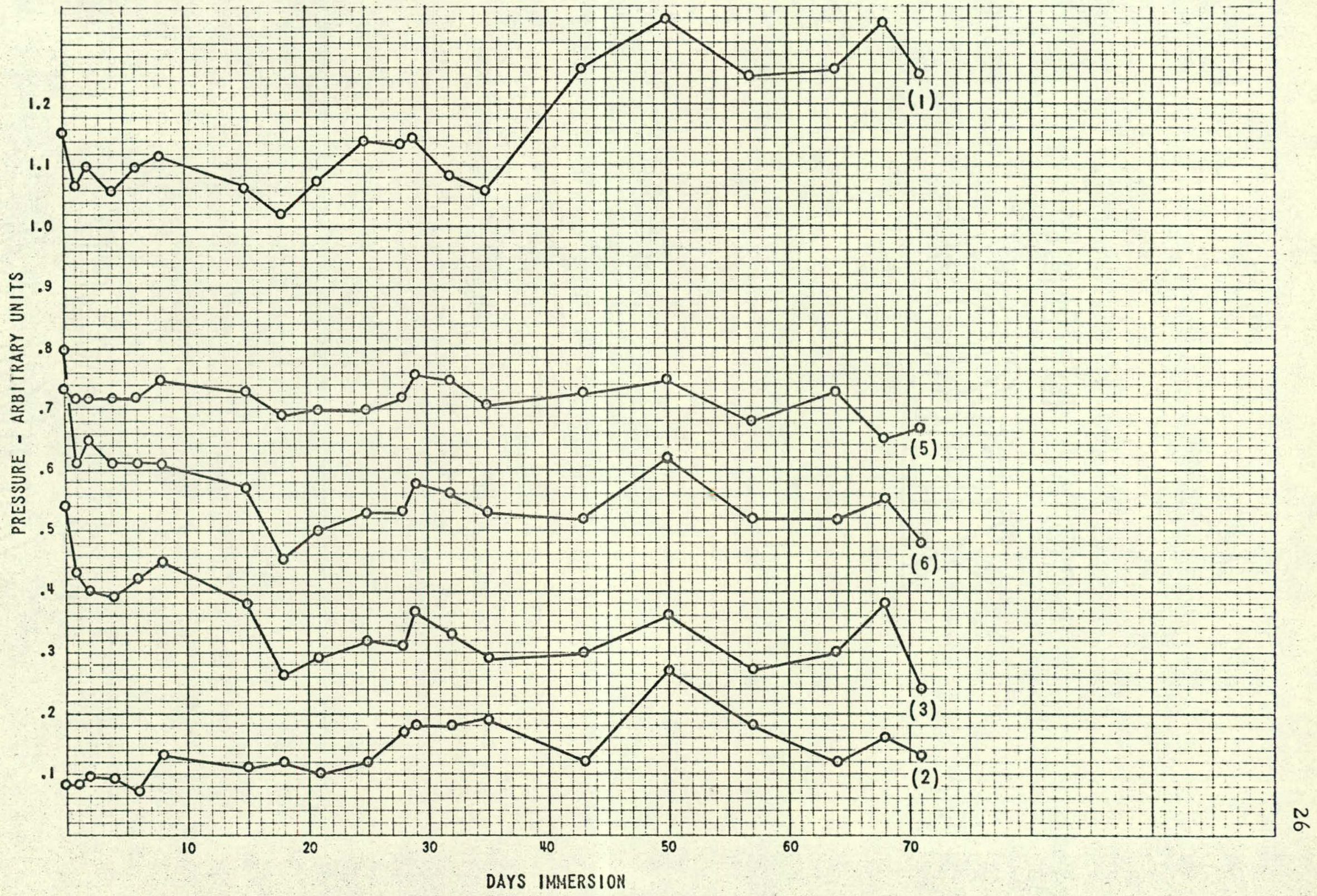


1. The use of low electrode voltages and low electron emission current, I milliampere, in order to minimize secondary emission and X-ray effects, inhibited the production of ions.

2. The electrical circuit used in conjunction with this tube type is not capable of measuring low pressures in the region of $10^{-8} \mathrm{~cm}$ of Hg. This is due to the high leakage currents and the inability to completely separate the positive ions produced by electron collisions with. gas molecules and the electrons which have sufficient thermal velocity to overcome the field at the grid and neutralize some of the positive charge by collision with the grid. This circuit is shown in Figure 4. 
FIGURE 4

\section{PRESSURE MONITORING \\ CIRCUIT USING \\ I2AU7}

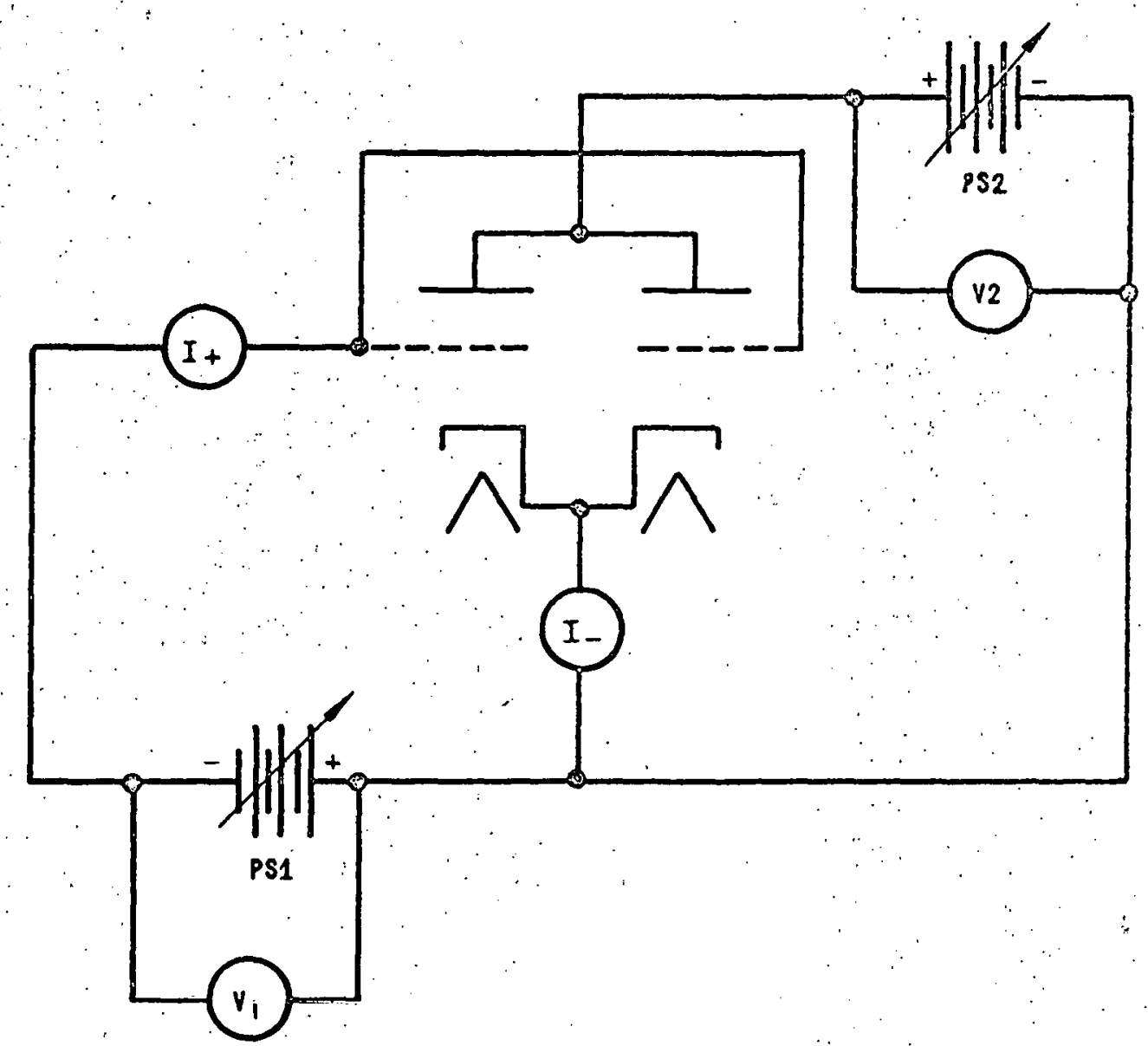

TUBE HEATERS OPERATING FROM $6.3 \mathrm{~V}$ AC SUPPLIED BY PS1

$$
\begin{aligned}
& \text { I+ HEWLETT PACKARD } 425 A \\
& \text { I- WESTON MOD } 931 \\
& \text { V1 WESTON MOD } 931 \\
& \text { V2 WESTON MOD } 931 \\
& \text { PS1 JOHN FLUKE MOD } 406 \\
& \text { PS2 JOHN FLUKE MOD } 406
\end{aligned}
$$




\section{CHAPTER IV}

\section{EXPERIMENT \#2}

The two circuits discussed previously for the first experiment failed to give the necessary sensitivity to ions in the low pressure range for the reasons already mentioned. For the second experiment it was necessary to utilize a different measurement technique.

A more sensitive gauge is the retarding field ionization gauge ${ }^{l}$ which is capable of measuring a minimum pressure of $5 \times 10^{-9}$ tor ${ }^{2}$. The circuit used in the experiment is shown in Figure 5. Two positive grids accelerate the electrons, a third grid with a negative charge repels the electrons back to the second and positive grid where the electrons are captured. The positive ions produced are accelerated by the third negative grid and, on passing through the grid are captured by the plate which is at a less negative voltage than grid number three. Figure 6 diagrams the action.

For this experiment, five 6BN6's were used. The 6BN6 was the only available tube which had approximately the desired electrode. configuration which would allow it to be connected as described for a retarding field gauge.

The operation of this experiment proceeded as follows: The five. tubes were divided into two groups. The control group consisted of 2 tubes. Three tubes were grouped for immersion in helium. Four tubes were Westinghouse Electric and one was a Sylvania. The Sylvania tube

${ }^{1}$ W. E. Dahlke and H. J. Schutze. 20th Annual Conference on Physicai Electronics M. I. T., Cambridge, Mass., March 26, 1960.

2 A torr is defined as 1333.22 Microbars or essentially $1 \mathrm{~mm}$ of $\mathrm{Hg}$. 
FIGURE 5

\section{RETARDING FIELD IONIZATION GUAGE CIRCUIT FOR MONITORING PRESSURE RISE}

6BN6

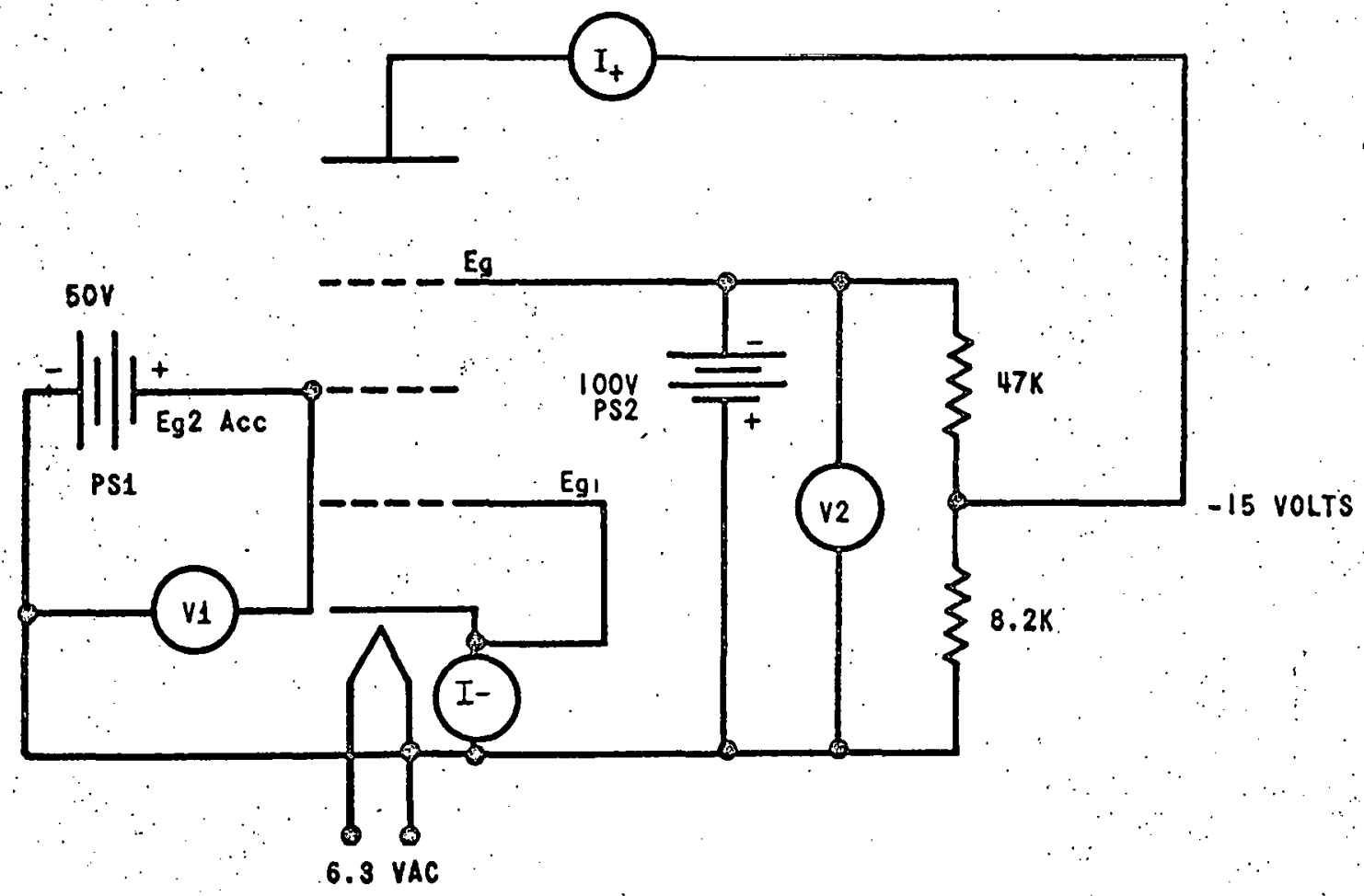

$I_{+} \therefore$ HEWLETT PACKARD MOD $425 A$ MICRO VOLTMETER

I- WESTON MODEL 93 I MILLIAMMETER

PS1 JOHN FLUKE MODEL 406

:PS2 JOHN FLUKE MODEL 406

VI WESTON MOD 931 VOLTMETER

V2 WESTON MOD 931 VOLTMETER 
FIGURE 6

\section{RETARDING FIELD IONIZATION GUAGE}

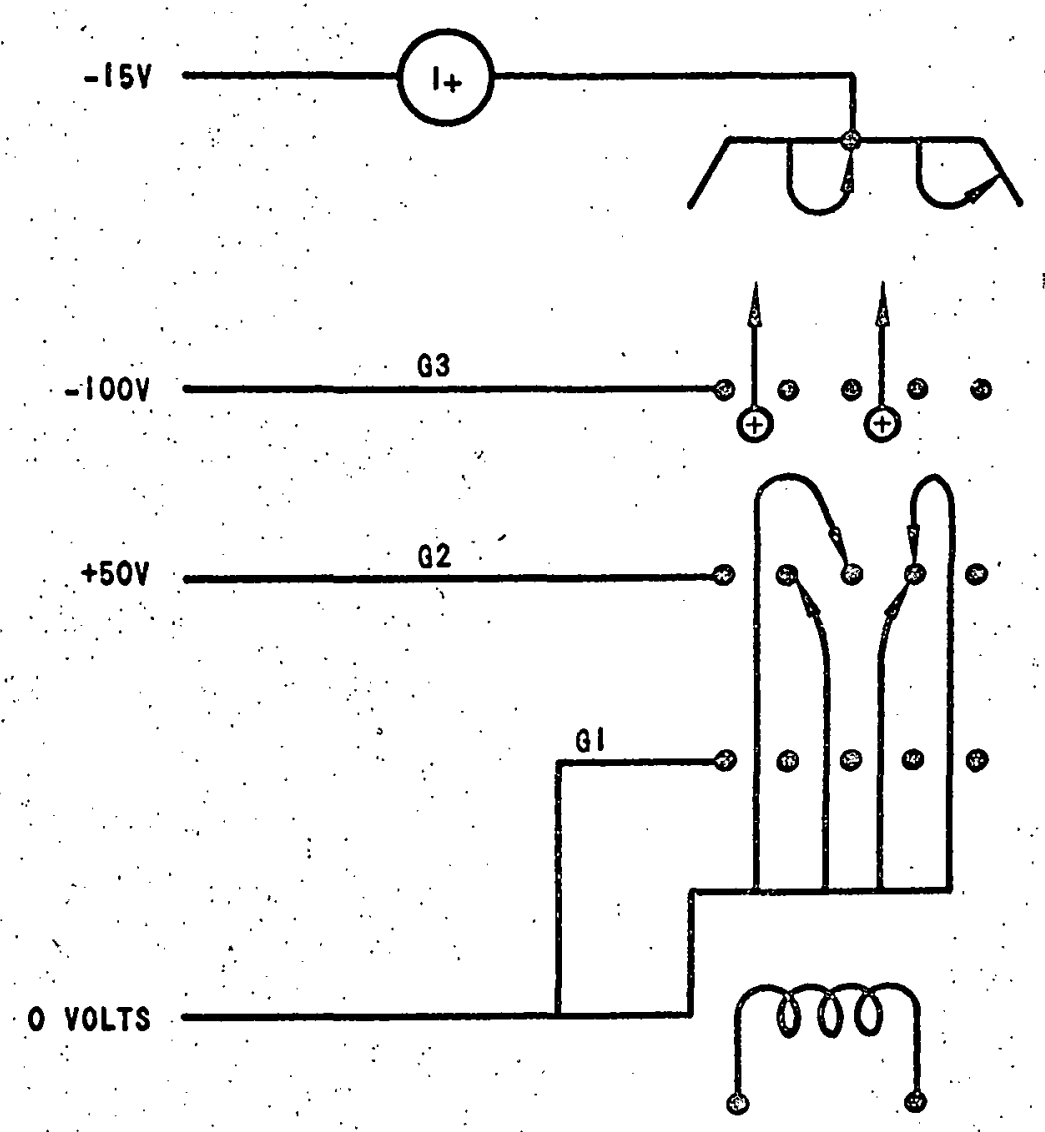


was grouped with those tubes to be immersed in helium because of possible correlation problems between the two control tubes if each were made by a different manufacturer. As later discovered, the Sylvania tube data was grouped with that of the Westinghouse Electric Tubes and did not show a significant difference in performance.

The immersed tubes were stored in a square aluminum box which had been machined from a solid billet. The overall dimensions were approximately 6"X6"X8". Minimum wall thickness was about 1 inch. The internal storage space was circular in shape and the box was threaded to accept a bronze cover to which was sweated a valve and a 4 foot length of $1 / 4$ " copper tubing with adapters on its extremity to mate with a helium gas bottle regulator and two gauges. One gauge indicated bottle pressure and the other gauge indicated the box pressure.

The three tubes were inserted in the aluminum box and sealed with the cover. The valve was opened and the complete system, box and copper line, evacuated with a vacuum pump. After pump down the valve was closed with the pump still running and then the copper line disconnected after shutting down the vacuum pump. The chamber was connected to the helium supply, the bottle valve cracked, pressure adjusted with the regulator and then the valve on the aluminum box opened. This provided essentially a pure helium environment for the tubes at the pressure indicated by the gauge on the regulator. Since there was very little gas loss in the all metal system, one helium bottle sufficed for this entire experiment.

For the readings, the tubes were removed from their container for a period sufficient to read and record data on all 5 tubes which 
amounted to less than one hour for all tubes and then the immersed tubes were immediately reinserted in their container.

Upon insertion of the tube in the circuit, a stabilization period of 5 minutes was allowed. At the end of this period a reading of the electron current and ion current was made and the tube immediately removed from the circuit. All of these readings are given in Table I Appendix C. It should be noted that Tube A, the Sylvania tube, was accidently dropped on the 115 th day and broken. It was removed from the tests and the plot of its data has been omitted from the curves since the data used in computation was obtained from the curves which occurred after 122 days.

For the first 122 days the storage pressure was 15 pounds per square inch, gauge. A graph of the ratio of ionization current to electron current versus days immersion is shown in Figure 7. The same parameter is also plotted for the two control tubes so their internal pressures can be compared to those tubes which were exposed to helium gas. It will be observed that all four tubes have an initial high pressure: which during the succeeding ten days falls rapidly and the slope gradually decreases out to 70 days where the curves are essentially level. This rapidly decreasing pressure is explained as follows: All of these tubes were selected from new stock. It is characteristic of vacuum tubes to outgas slightly when out of service and lying on the shelf. Operation of the tubes provides ion pumping and a gettering action which traps the occluded gases. This action was not anticipated and any slight pressure build-up due to helium permeation was masked by the greater degassing effect indicated in Figure 7 by the rapid decrease in 
FIGURE 7

\section{RELATIVE INTERNAL TUBE PRESSURE VS TIME}

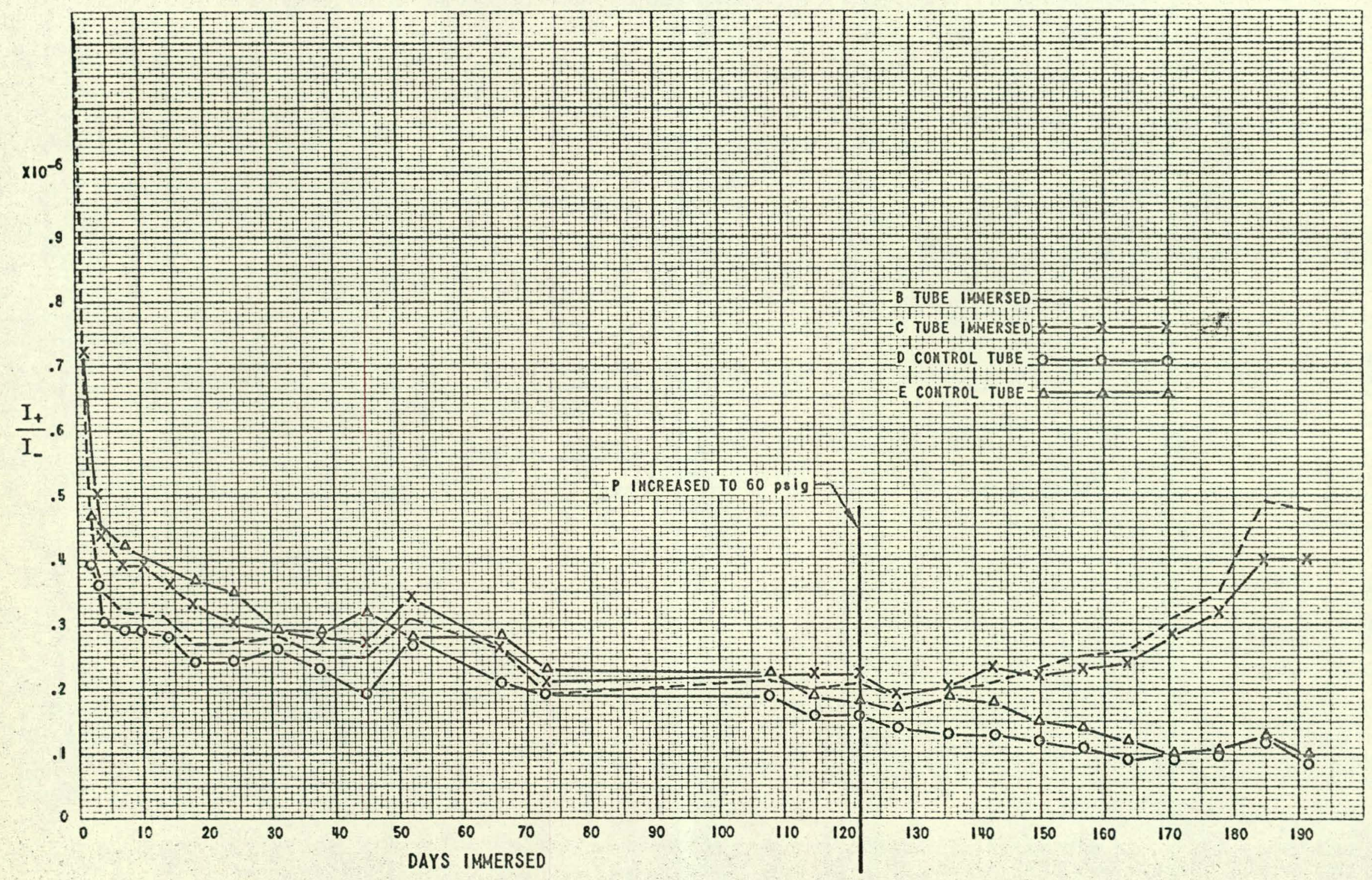


pressure. However; this did not effect the experiment because the tubes were outgassed by the 122 nd day.

The total operating time for any one tube for the 73 day interval was 80 minutes since each tube was only operated five minutes for each reading. If the tubes had been previously "aged" for several hours the initial readings would have been at minimum pressure. This is verified by Tube $A$ which was used previous to the experiment for two hours in determining optimum electrode voltages in the retarding field circuit. A plot of values obtained from Table I will show this.

Since permeation rate is proportional to pressure difference, the experiment was accelerated by increasing the helium pressure to 5 atmospheres differential after the reading on the 122 nd day. This day is considered zero time for all succeeding calculations and initial tube pressure is based on the internal pressure at this time.

Figure 8 shows a plot of the raw data taken for the last 92 days of the experiment. The gradual decline of the control tubes' pressure can be compared to the reverse slope pressure rise taken by the tubes subjected to the helium environment.

To obtain a true picture of the pressure increase in the tubes subjected to the helium gas and to account for instrumentation vagaries the average of the control tube curves was used as a basis for obtaining correction factors to add or subtract from the values for the soaked tubes. The starting reference points are the values obtained for the 122nd day. Examination of the curves in Figure 7 show that the heavy outgassing had leveled off and, following these readings, the external pressure on the soaked tubes was raised to 60 psig or essentially a 5 atmospheres differential pressure applicd across the glass walls of 


\section{RELATIVE INTERNAL TUBE PRESSURE VS TIME IN DAYS}

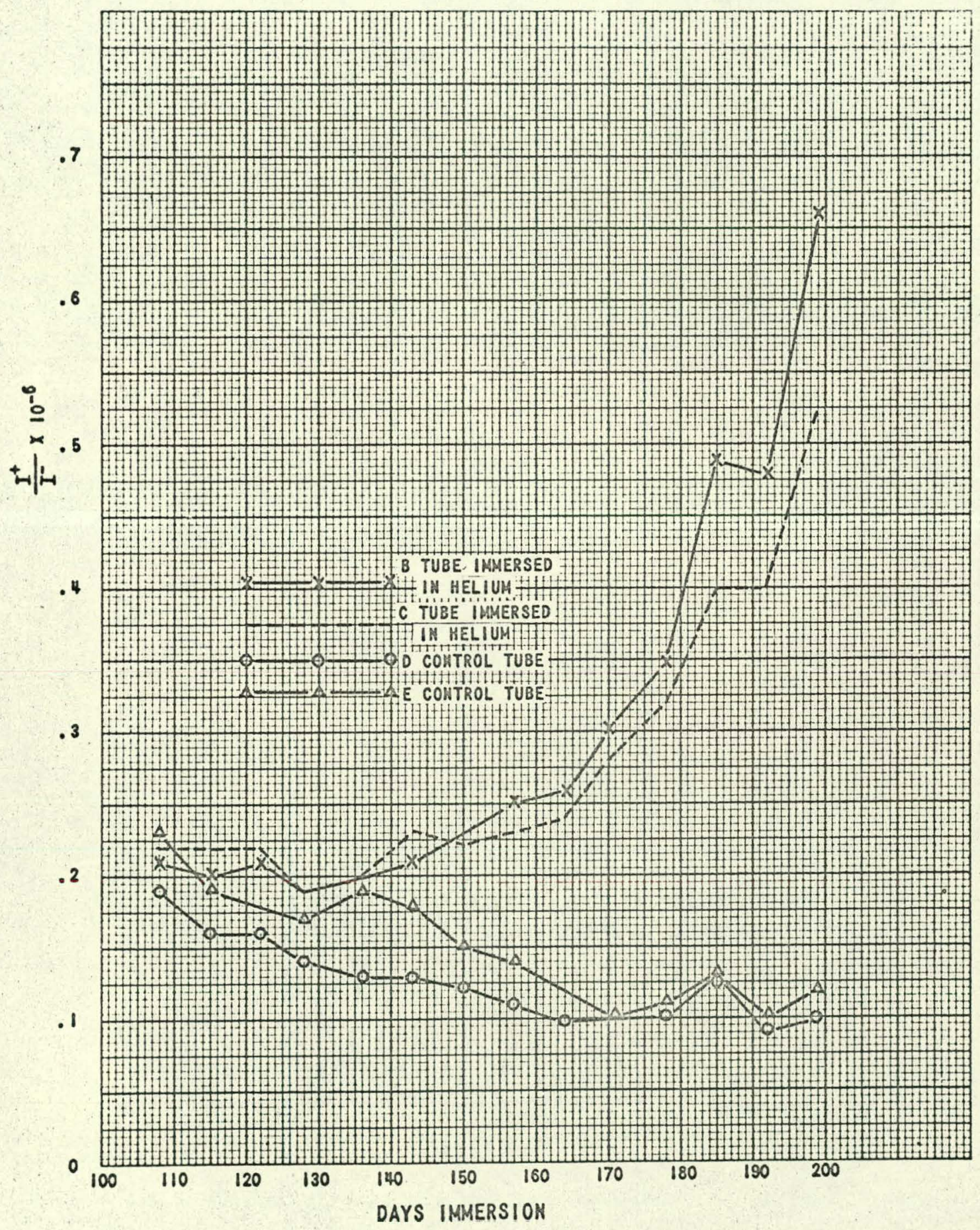


the tubes.

For every interval of measurement when the average value of control tube pressure decreased, it can be assumed with some degree of confidence that the internal pressure of the tubes exposed to helium would also have decreased except for the permeation of helium through the glass at a sufficient rate to offset the pressure decrease occurring in the unexposed tubes. Moreover, the rate was sufficiently great to increase the internal tube pressure. For every decrease in the control tube readings during one measurement interval, this difference was added to the values obtained for the tubes under gas pressure. Similarly, for every increase in the average control tube readings, the difference for the measurement interval was subtracted.

The curves of tubes (B) and (C) have been corrected and smoothed as shown in Figure 9. In addition, the linear part of each curve has been extended down to the $p=0$ axis. The reason for this will be developed later.

\section{CALCULATIONS}

The physical data for the $6 \mathrm{BN} 6$ vacuum tube is as follows:

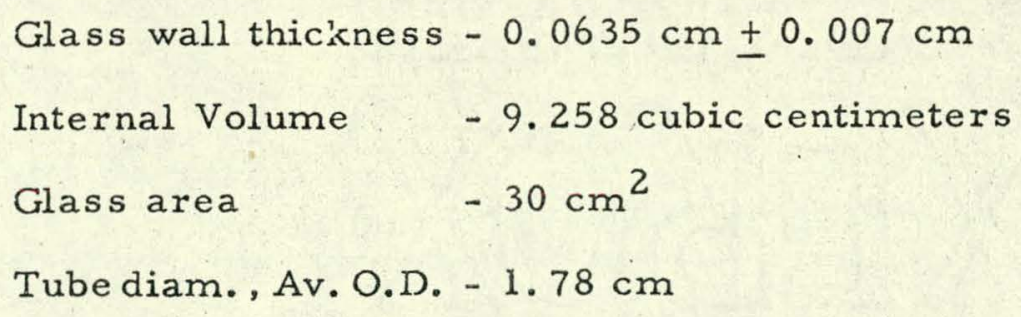

First, convert the $\frac{I+}{I-}$ values into pressure. After pressure is determined, the pressure rise per unit time can be measured from the slope of the linear part of the curve in Figure 9. From

$$
Q=V \quad \frac{\Delta P}{76 t}
$$




\section{RELATIVE INTERNAL PRESSURE OF TUBES VS TIME IN DAYS}

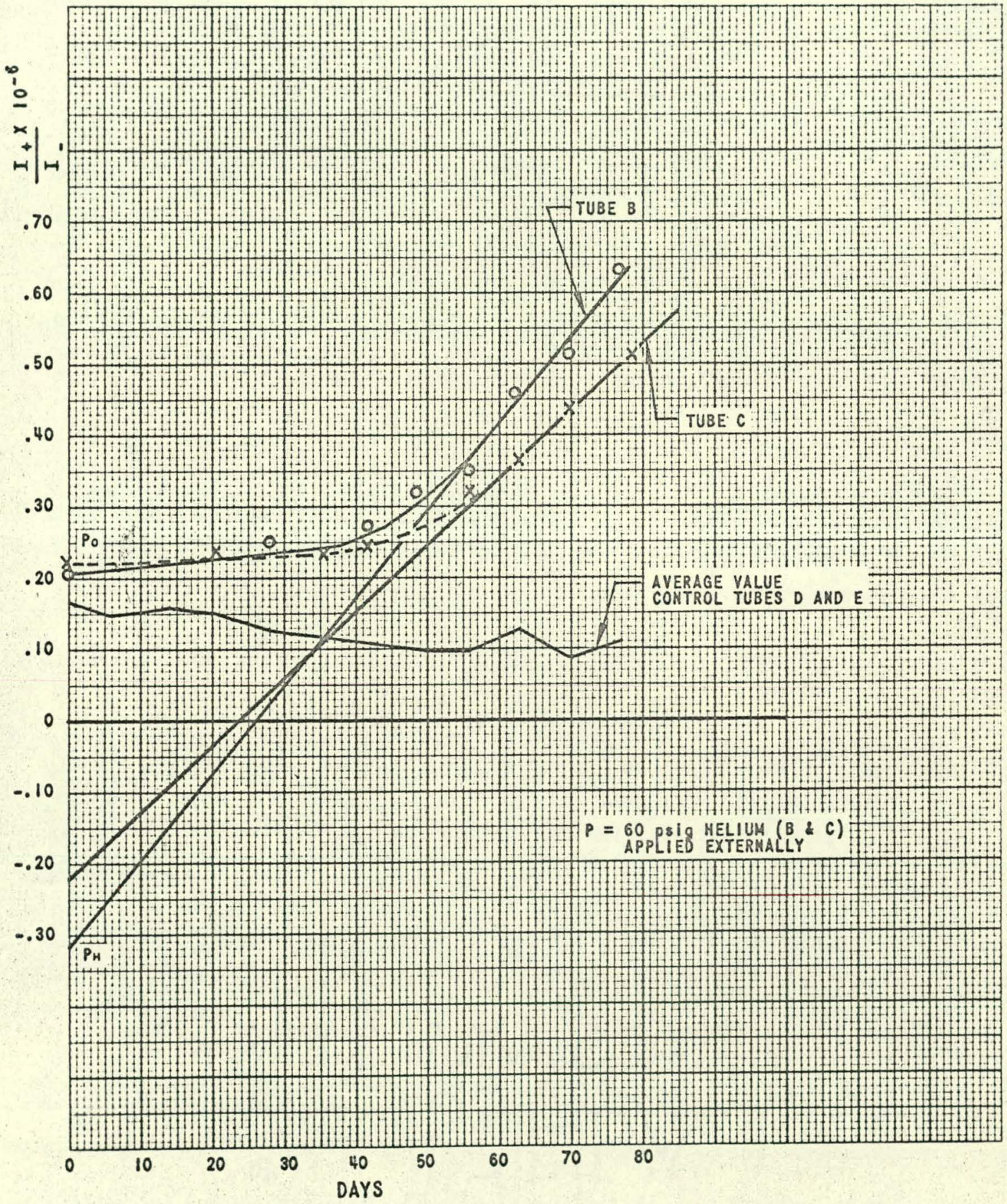


where $\mathrm{V}=$ Internal Tube Volume $\left(\mathrm{cm}^{3}\right)$

$$
\begin{aligned}
& \frac{\Delta P}{t}=\text { Pressure rise per unit time }(\mathrm{cm} / \mathrm{sec}) \\
& 76=\text { converts } Q \text { to N.T.P. (cm) }
\end{aligned}
$$

the flow rate $Q$ (cc/sec) will be known.

The total quantity, $Q$, in terms of the Permeation Velocity, $K$, is given by ${ }^{3}$

$$
\begin{aligned}
& q=\operatorname{KAt}\left(p_{2}-p_{1}\right) \\
& \text { where } \mathrm{K}=\text { permeation velocity constant. Units } \\
& \text { commonly used are: } \mathrm{cm}^{3} \text { gas (N.T.P.) } \\
& / \mathrm{second} / \mathrm{cm}^{2} \text { area/mm thickness/unit } \\
& \text { difference in partial pressure }(\mathrm{cm} \text { of } \mathrm{Hg}) \text {. } \\
& A=\text { glass area in } \mathrm{cm}^{2} \text {. } \\
& t=\text { second } s \\
& \mathrm{p}_{2}=\text { External gas pres sure in cm. } \\
& \mathrm{p}_{1}=\text { Internal gas pressure in } \mathrm{cm} \text {. } \\
& \mathrm{d}=\text { glass thickness in } \mathrm{mm} \text {. }
\end{aligned}
$$

The quantity, $q$, is in cubic centimeters. For the experiment where $p_{2}$ is 5 atmospheres, the internal pressure $p_{1} \cong 0$. It is obvious that if the internal pressure $p_{1}$ is $1 \times 10^{-6} \mathrm{~cm}$. then the difference $p_{2}-p_{1}$ will be essentially equivalent to $p_{2}$.

It was previously noted that the straight portion of the two immersed tube curves had been projected back to intercept the time axis and the $p=0$ axis as seen in Figure 9. This was done as equations (25), through (29) Chapter II explained. From Figure 9, tube B intercept at the time axis is 26 days, tube $C$ at 24 days. The $p=0$ intercept occurs at -.33 and -.22 for $B$ and $C$ respectively.

${ }^{3}$ G. J. VonAmerongen. Permeability of Rubbers to Gasses. Journal of Applied Physics 17, $972 . . \overline{851916 .}$ 
The time $\operatorname{lag} t_{c}$, is sumetimes referred to as the characteristic: time, 4 the characteristic time being a measure of the time requirvd to establish a constant flow. From (26)

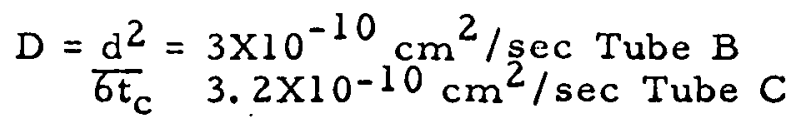

where $d=0.0635 \mathrm{~cm}$

$$
\begin{aligned}
t c= & 2.24 \times 10^{6} \text { sec for } B, \\
& 2.07 \times 10^{6} \text { sec for } C .
\end{aligned}
$$

The Diffusion Coefficient, D, is not dependent on pressure. Altemose 5 gives a value for Corning 0080 glass at $394^{\circ} \mathrm{C}$ of $7.6 \times 10^{-7} \mathrm{~cm}^{2} / \mathrm{sec}$. Correcting for temperature from 6

$$
D=D_{0} e^{\frac{-Q}{R T}}
$$

where $Q=$ activation energy (cal/mole); Corning 0080 is 11000 for helium gas?

$$
\begin{aligned}
& R=\text { gas constant }\left(1.986 \mathrm{cal} / \mathrm{mole}^{\circ} \mathrm{C}\right) \\
& T=\text { absolute temperature } \\
& D_{0}=\begin{array}{l}
3.12 \times 10^{-3} \mathrm{~cm}^{2} / \mathrm{sec} \text { determined from solu- } \\
\text { tion of }(\mathrm{Eq} 4) \text { at } 394^{\circ} \mathrm{C},
\end{array}
\end{aligned}
$$

the value of $\mathrm{D}$ at $21^{\circ} \mathrm{C}$ is calculated to be $2.2 \times 10^{-11}$. For comparison of calculated and observed values of $\mathrm{D}$ at $\mathrm{T}=21^{\circ} \mathrm{C}$,

$$
\begin{array}{ll}
\text { Altemose } & 2.2 \times 10^{-11} \mathrm{~cm}^{2} / \mathrm{sec} \\
\text { Experiment: Tube B } 3 \times 10^{-10} \mathrm{~cm}^{2} / \mathrm{sec} \\
\text { Experiment: Tube C } 3.2 \times 10^{-10} \mathrm{~cm}^{2} / \mathrm{sec}
\end{array}
$$

From $[$ Eq (3)] the Permeation Velocity $\mathrm{K}$ may be determined by solving for $\mathrm{K}$ :

${ }^{4}$ Rogers, Buritz and Alpert. Diffusion Coefficient, Solubility, and Permeability for Helium in Glass. Journal of App'd. Physics. V25 N7, July, 1954, Page 870.

5 V. O. Altemose. op. cit.

${ }^{6}$ Rogers, et al op. cit.

${ }^{7}$ V. O. Altemose. op. cit. 


$$
K=\left(\frac{q}{t}\right) \frac{d}{A\left(p_{2}-p_{1}\right)}
$$

The quantity $\left(\frac{q}{t}\right)$ is measured in cubic centimeters/second and is the flow rate which was measured directly by Norton ${ }^{8}$ and Altemose 9 using the mass spectrometer. The mass spectrometer is very accurate for this purpose because it can be made to respond to only the permeating gas excluding all other gases, and it can be calibrated with known quantities of a specific gas.

Since mass spectrometry was not used in this experiment, resort. was made to determining the $\frac{\mathrm{q}}{\mathrm{t}}$ leakage rate from $[\mathrm{Eq} \cdot(2)]$.

This approach is not as accurate as the mass spectrometer because the actual tube internal pressure is not known with any certainty but must be assumed for the initial value and the gauge constant $k$ then determined from this assumption. It was also assumed from the first day that any pressure change was due only to helium gas and that the gauge constant (k) which was determined from the straight line intercepts remained constant over the pressure range measured.

The tube $B$ intercept on the pressure axis is at $(-.33)$ as shown in Figure 9. The straight line extension from the curve back toward the $t=0$ axis would represent the helium pressure increase from the beginning of the experiment if there were no time lag. The intercept, therefore, at the $t=0$ axis represents the tubes' initial internal helium pressure and therefore point $\mathrm{P}_{\mathrm{H}}$ should equal the pressure represented by $P_{0}$ for other gases since the helium, due to the time lag had not

\footnotetext{
${ }^{8}$ F.j. Norton. op. cit.

9 V. O. Altemo se. op. cit.
} 
started to permeate the envelope. The two points, $P_{0}$ and $P_{H^{\prime}}$ are identified in Figure 9.

$P_{0}$ for tube $B$ is 54 units above $P_{H} \cdot P_{H}$ is also affected by the. ratio of ionization efficiency ${ }^{10}$ of $\mathrm{N}_{2}$ which is 9 for an electron energy of 50 volts. For $P_{0}$ to equal $P_{H}$

$$
\begin{aligned}
& \dot{P}_{H}=\frac{1}{(54 \times 9)} P_{0} \\
& P_{H}=.00206 P_{0}
\end{aligned}
$$

or

$$
k=.00206 \text { Tube } B
$$

and similarly

$$
k=.00252 \text { Tube } C
$$

From Figure 9 the ratio of $\frac{I t}{I-}$ increase per day $=0.12 \times 10^{-7}$ for Tube $B$ and $0.09 \times 10^{-7}$ increase per day for Tube $C$. The rate of pressure increase, from [Eq. (I)], per day is:

$$
\begin{aligned}
.12 \times 10^{-7} & =.00206 \mathrm{P} \\
\mathrm{P} & =5.84 \times 10^{-6} \mathrm{~cm} / \text { day } \quad \text { Tube B } \\
\mathrm{P} & =3.57 \times 10^{-6} \mathrm{~cm} / \mathrm{day} \quad \text { Tube C }
\end{aligned}
$$

Utilizing [Eq. (2)] where $V=9.26 \mathrm{~cm}^{3}, t=1$ day $\left(8.64 \times 10^{4} \mathrm{sec}\right)$ :

for Tube $B$

$$
\begin{aligned}
& \dot{Q}=\frac{(9.26)\left(5.84 \times 10^{-6}\right)}{\left(8.64 \times 10^{4}\right)\left(.76 \times 10^{2}\right)} \\
& Q=8.26 \times 10^{-12} \mathrm{cc} / \mathrm{sec}
\end{aligned}
$$

and Tube $\dot{C}$

$$
Q=5.03 \times 10^{-12} \mathrm{cc} / \mathrm{sec}
$$

Substituting (Q) for $\frac{\mathrm{q}}{\mathrm{t}}$ in Eq. (5) for Tube B:

$$
\begin{gathered}
K=\left(8.26 \times 10^{-12}\right)(.635)=.46 \times 10^{-15} \mathrm{cc} / \mathrm{sec}^{-1} / \mathrm{cm}^{2} / \\
\mathrm{mm} / \mathrm{cm} \text { of } \mathrm{Hg}
\end{gathered}
$$

Tube $\dot{\mathrm{C}}: \quad \mathrm{K}=$ $.28 \times 10^{-15} \mathrm{cc} / \mathrm{sec} / \mathrm{cm}^{2} /$ $\mathrm{mm} / \mathrm{cm}$ of $\mathrm{Hg}$

${ }^{10}$ Compton and Van Voorhis; op.cit. 
Altemose ${ }^{11}$ gives $K$ for Code 0080 glass at $291^{\circ} \mathrm{C}$ as $2.5 \times 10^{-11}$. Correcting for temperature again yields a $\mathrm{K}$ value at $21^{\circ} \mathrm{C}$ of $3.2 \times 10^{-15}$ $\mathrm{cc} / \mathrm{sec} / \mathrm{cm}^{2} / \mathrm{mm}$ thickness $/ \mathrm{cm}$ of $\mathrm{Hg}$ diff. Norton's ${ }^{12}$ value for $K$ at $25^{\circ} \mathrm{C}$, which is compared directly due to only $4^{\circ} \mathrm{C}$ temperature difference, is $7.5 \times 10^{-15}$.

For comparison, the permeation constants are given again:

Experiment Tube B: $0.46 \times 10^{-15} \mathrm{cc} / \mathrm{sec} / \mathrm{cm}^{2} / \mathrm{mm} / \mathrm{cm}$ of $\mathrm{Hg}$ diff.

Experiment Tube C: $0.28 \times 10^{-15}$

$\begin{array}{ll}\text { Altemose } & : 3.2 \times 10^{-15} \\ \text { Norton } & : \quad 7.5 \times 10^{-15}\end{array}$

Two methods may be used to determine $S$, the solubility factor. One is to use the relationship of [Eq. (9)] , Chapter II, where $\mathrm{K}$ is . now substituted for P. The other method uses [Eq. (29)] , Chapter II, in conjunction with the pressure intercept at $t=0$ in Figure 9. Solutions to both methods are determined and the results compared. Neither method will provide a greater accuracy over the other since both are derived from the empirical data which has been plotted in Figure 9.

Rearranging [Eq. (9)] the units of $S$ are cc/cc-atmosphere in order to compare the results with those published by Altemose. 13

$$
S=\frac{K}{D}=\frac{.46 \times 10^{-16}}{3 \times 10=10}(76)=1.16 \times 10^{-5}
$$

For Tube B: $\quad S=1.16 \times 10^{-5} \mathrm{cc} / \mathrm{cc}-\mathrm{atm}$

For Tube C: $\quad S=6.65 \times 10^{-6} \mathrm{cc} / \mathrm{cc}-\mathrm{atm}$

11 V. O. Altemose. op. cit.

12 F. J. Norton. op. cit.

13 Altemose. op. cit. 
Using the second method a sample calculation for Tube B Solubility (S):

$$
\begin{aligned}
& \mathrm{S}=\frac{6 \mathrm{~V}_{\mathrm{T}} \mathrm{P}_{\mathrm{T}}}{\mathrm{Adp} 2}=-6 \frac{(\mathrm{cc} \text { of gas at } \mathrm{NTP})}{(\mathrm{cc} \text { of glass })(\mathrm{ATM})} \\
& \text { where } V_{T}=\text { Tube Volume }\left(9.26 \mathrm{~cm}^{3}\right) \\
& P_{T}=\text { Tube Pressure }=\frac{(I+)}{I-} \frac{(1)}{k} \text { at } t=0 \\
& P_{A}=\text { Standard Atmosphere }(76 \mathrm{~cm}) \\
& V_{A}=(N \cdot T \cdot P \cdot)=\frac{P_{T} V_{T}}{P_{A}}=\frac{P_{T} V_{T}}{76} \\
& A=\text { Glass area }\left(\mathrm{cm}^{2}\right) \\
& \mathrm{d}=\text { Glass thickness }(\mathrm{cm}) \\
& \mathrm{p}_{2}=\text { External pressure (atm) } \\
& S=-6 \frac{\left(.21 \times 10^{-6}\right)(9.26)}{\frac{(.00206)(76)}{(30)(.0635)(5)}} \\
& \mathrm{S}=-.79 \times 10^{-5} \mathrm{cc} / \mathrm{cc}-\mathrm{atm} \\
& \text { For Tube C: . } S=-.67 \times 10^{-5} \mathrm{cc} / \mathrm{cc}-\mathrm{atm}
\end{aligned}
$$

The negative value is a result of the method used to obtain the equation and has no significant meaning for the solubility constant.

The calculated values of $S$ are presented for comparison: units are cc/cc atmosphere.

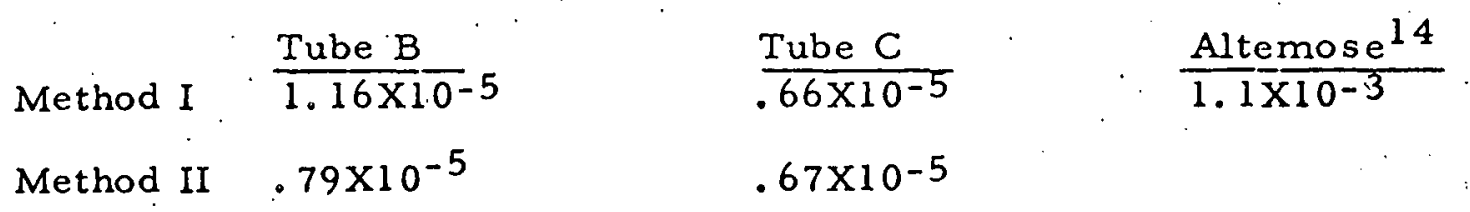

It should be noted that the values presented as obtained by Altemose and Norton have had a temperature correction factor applied. The

14 Ibid: 
Lowest temperature used by Altemose ${ }^{15}$ for determining the characteristics of Code 0080 glass was $291^{\circ} \mathrm{C}$ and by Norton $16,25^{\circ} \mathrm{C}$. Correcting for temperature was done to provide a comparison with values of $\mathrm{K}$, S, and D obtained by others.

Comparison of values obtained for Permeation Velocity, Diffusion and Solubility constants with the values obtained by Norton 17 and Altemose ${ }^{18}$, can be made by reference to Table 2 .

The differences in values are explained by the differences in techniques used in obtaining the values. This work used the ionization of the permeating gas to determine the permeation rate by measuring the pressure rise in a known volume. The gauge constant, ionization efficiency and instrumentation which was used over a period of 100 days were optimistically assumed to behave predictably and according to known history. At best, the graphical solution is still the "poor man's calculus", quite effective in verifying Ficks' law of Diffusion but not as accurate or sophisticated as the mass spectrometer. Altemose 19 summed it up:

"It is felt that the simplicity, accuracy, and selectivity of the mass spectrometer for permeation measurements again deserves mention. In practically all high vacuum work, especially where temperature variations are used, there will generally be a certain amount of system outgassing. The presence of these extra gases is not easy to account for when using an ion gauge or other pressure

15 Tbid.

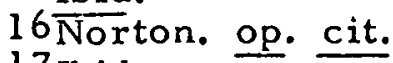

17 Ibid.

18 Norton. op. cit.

19 Altemose. op. cit. 
TABLE 2

\section{EXPERIMENTAL RESULTS FOR PERMEATION VELOCITY, SOLUBILITY AND DIFFUSION COEFFICIENTS COMPARED TO THOSE OBTAINED BY NORTON" AND ALTEMOSE ${ }^{22}$}

\section{EXPERIMENT}

NORTON

ALTEMOSE

\section{PERMEATION}

VELOCITY K

$0.40 \times 10^{-15}$ TUBE B

$7.5 \times 10^{-15}$

$3.2 \times 10^{-15}$

$\mathrm{CC} / \mathrm{CM}^{2} / \mathrm{SEC} / \mathrm{MM} /$

$\mathrm{CM}$ of $\mathrm{Hg}$ diff.

$0.28 \times 10^{-15}$ TUBE $C$

SOLUBILITY S

$1.16 \times 10^{-5}$ TUBE $B$.

$1.1 \times 10^{-3}$

CC/CC-ATM

$0.66 \times 10^{-5}$ TUBE $C$

DIFFUSION D

$3 \times 10^{-10}$ TUBE $B$

$2.2 \times 10^{-11}$

$\mathrm{CM}^{2} / \mathrm{SEC}$

$3.2 \times 10^{-10}$ TUBE $C$ 
gauge to determine permeation rates-

The technique of employing the glass vacuum tube as described in the experiments has the advantage over the mass spectrometer method in being able to determine approximately the permeation rate of helium through the glass without destroying the tube. This technique has value in that a tube exposed to a helium atmosphere may be connected as any ionization gage and its readings compared with those of an unexposed tube. From the comparison of readings an estimate can be made of the degradation of the exposed tube. 


\section{CONCLUSIONS}

There are two main purposes to this experiment:

A. Verification of the analytical results stated in (23) Chapter II, which was obtained by applying appropriate boundary conditions to the Fick's Diffusion Law. This equation states that with a pressure differential of a gas with a known permeation velocity constant for a particular membrane material, after a time lag dependent upon the diffusion coefficient of the membrane, the internal pressure will increase linearly with time. This equation, (23), is given again:

$$
\begin{aligned}
& P=\frac{A D S}{V d}\left[\left(p_{2}-p_{1}\right) t-\frac{p_{2} d^{2}}{6 D}-\frac{p_{1} d^{2}}{3 D}\right] \\
& P=\text { Internal pressure }(\mathrm{cm}) \\
& A=\text { Glass Area }\left(\mathrm{cm}^{2}\right) \\
& D=\text { Diffusion coefficient }\left(\mathrm{cm}^{2} / \mathrm{sec}\right) \\
& S=\text { Solubility, dimcnsionless } \\
& V=\text { Internal Tube Volume }\left(\mathrm{cm}^{3}\right) \\
& \mathrm{d}=\text { glass thickness (cm) } \\
& \mathrm{t}=\text { seconds } \\
& \mathrm{p} 2=\text { External pressure }(\mathrm{cm} \text { of } \mathrm{Hg} .) \\
& \mathrm{pl}=\text { Internal pressure }(\mathrm{cm})
\end{aligned}
$$


B. Utilize these experimental results in an attempt to verify, within a reasonable value, the permeation constant, $K$, obtained by others ${ }^{1,2}$ who have used the more exact mass spectrometric measurements.

It has been shown that glass vacuum tubes when exposed to an environment of helium gas will undergo an internal pressure increase. The rate of increase is dependent on the glass material comprising the envelope, external helium pressure and temperature. Norton ${ }^{3}$ has shown that for a Soda-lime, Code 0080 glass, the Permeation Constant $\mathrm{K}$ at $100^{\circ} \mathrm{C}$ is 300 times the $\mathrm{K}$ at $25^{\circ} \mathrm{C}$. This means that the expected operating life of a vacuum tube made of Code 0080 glass would be 1/300 of its normal life if the tube were sealed in a helium atmosphere.

The Soda-lime, Code 0080, glass; has a low $\mathrm{K}$ factor and is used in standard commercial receiving tubes such as the type $12 \mathrm{AUT} 7^{4}$. Another glass, Code 7720, a Borosilicate, is used in tubes which operate at higher temperatures. This glass has a $\mathrm{K}$ factor greater than the Code 0080 glass. The effect of helium on the operation of

${ }^{1}$ V.O. Altemose. Helium Diffusion Through Glass. Journal of Applied Physics. V32N7, July 1961.

${ }^{2}$ F. J. Norton. Helium Diffusion Through Glass: Journal of the American Ceramic Society. V36N3, March 1953.

${ }^{3}$ Norton . op. cit.

${ }^{4}$ Correspondence-Sylvania Electric Products Inc. April 13, 1961. 
Hydrogen Thyratrons ${ }^{5}$ is shown in Figure 10. In Figure 11, the effect of helium on the power output of a planar triode ${ }^{6}$ graphically shows the degrading of a tube as the result of sealing in a helium environment. Continued exposure such as might be received in a hermetically sealed electronic subassembly which has been backfilled with helium gas preparatory to leak detection would lead to further degradation and ultimate functional failure.

Elimination of the problem of tube degradation can be obtained:

A. In low power applications, semiconductors can replace vacuum tubes. Semiconductors are not influenced by inert gas permeation since their operation does not depend on free electron flow through space. There is also the bonus feature of heat elimination, since semiconductors are devoid of filaments.

B. For those designs employing vacuum tubes, the disadvantages encountered with helium gas can be avoided by the simple expedient of using another inert gas; Argon, for example is one choice. However, since Argon doesn't have the high diffusive properties of helium relative to air, .87 for Argon and 2.64 for Helium, greater concentrations will be needed to achieve reasonable leak detection sensitivity.

${ }^{5}$ S. J. Catalano. Investigation of Helium Permeation into the Thyratron. Unpublished, Bendix K. C. D. Dec. $28,1959$.

${ }^{6}$ H.F. Jordon. Helium Permeation of the Electron Tube, Unpublished, Bendix K. C.D. February $11, \overline{1960 .}$ 


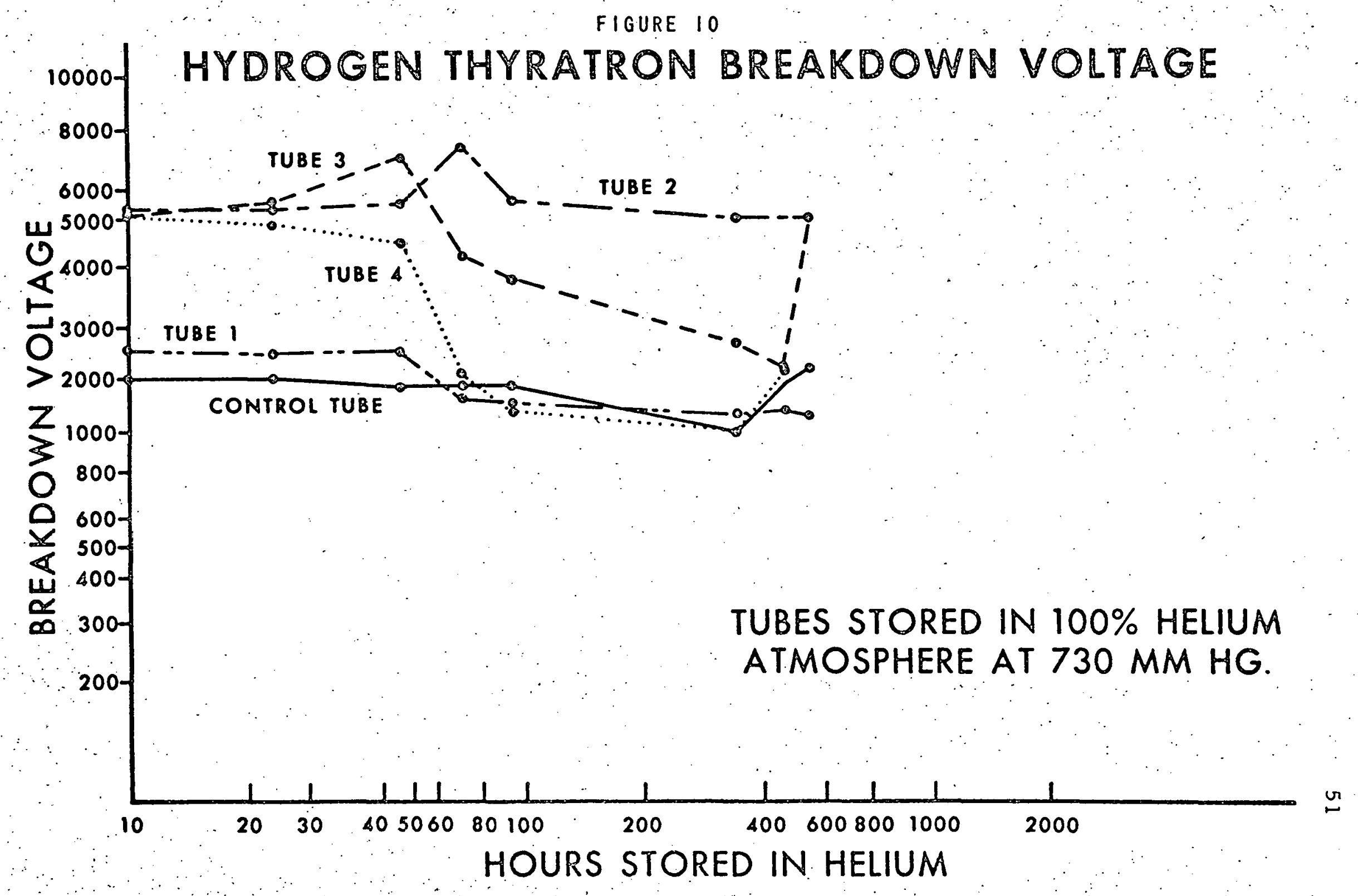




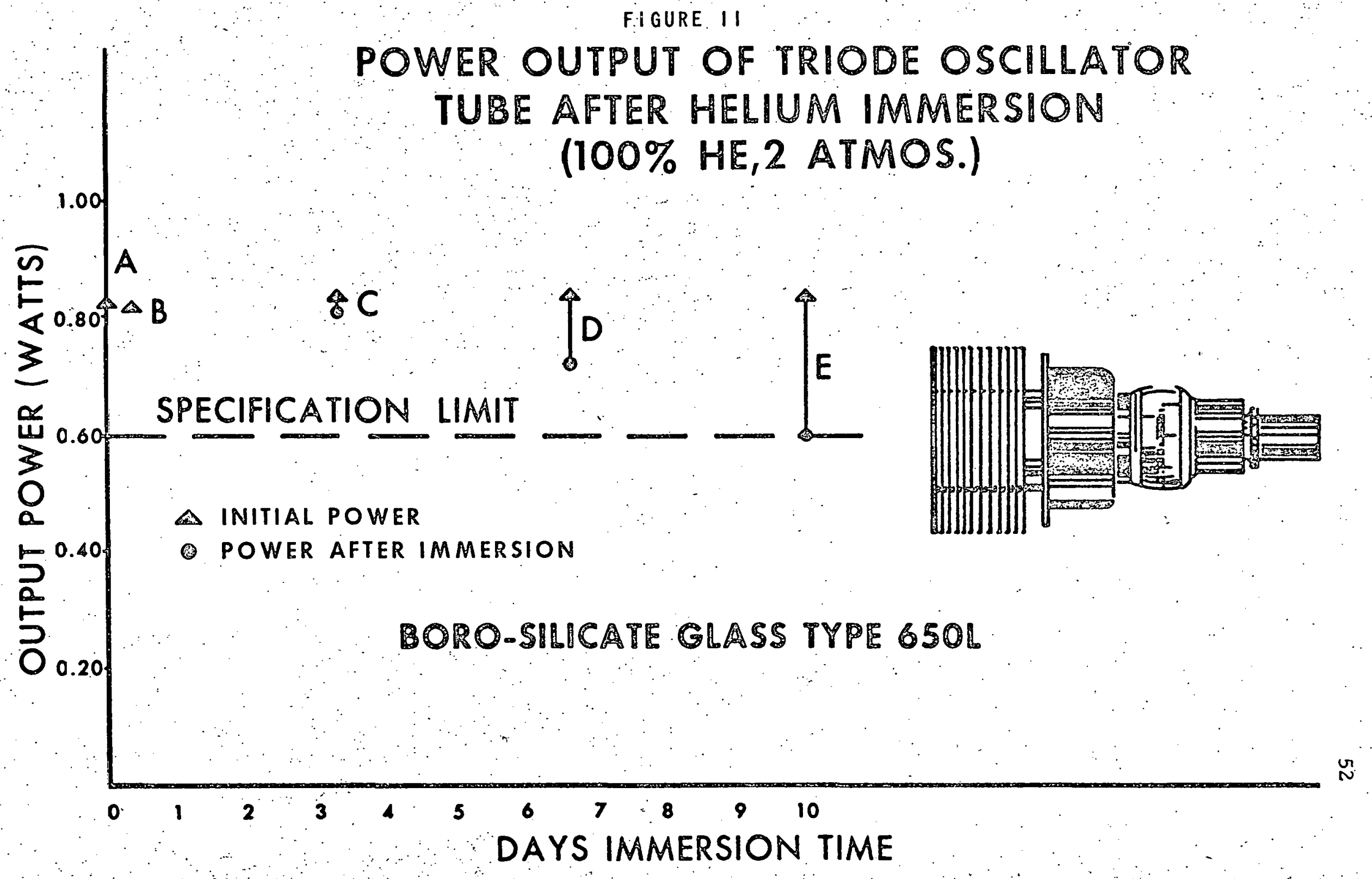


Although not as accurate a method as the mass spectrometer technique, the method described herein has the advantage in that the sample under investigation can remain intact to make the permeation: measurements.

The accuracy of measurements are within one order of magnitude for the accepted value of $K$. This in considered a reasonable accuracy for this technique because the internal tube pressure was assumed; the internal pressure exerts the greatest influence on the ultimate accuracy of the measurements.

Finally, the method which has been developed in this thesis provides a convenient technique for determining the Helium permeability characteristics of electron tubes without employing external leak detection devices. 


\section{BIBLIOGRAPHY}




\section{BIBLIOGRAPHY}

Books

Barrer, R. M. Diffusion In and Through Solids. Cambridge, 1951.

Cambel, A. B. and Jennings, B. H. Gas Dynamics. McGraw Hill 1958.

Carslaw, H. S. and Jaeger, J. C. Conduction of Heat in Solids.

Clarendon Press, Oxford 1947. pp 2-9.

Crank, J. Mathematics of Diffusion. Oxford 1956.

Guthrie, A. and Wakerling, R. Vacuum Equipment and Techniques McGraw-Hill 1949 p8.

Kohl, W. H. Materials Technology for Electron Tubes. Reinhold Pub:

Wylie, C. R. Ir. Advanced Engineering Mathematics. McGraw-Hill, 1951.

Periodicals

Altemose, V. O. Helium Diffusion Through Glass. Journal of Applied Physics. V32N7, July 1961.

Compton, K. T. and Van Voorhis, C. C. Physics Review V27, 1926, p. 724.

Dahlke, W. E. and Schutze, H. J. 20th Annual Conference on Physical Electronics M. I. T., Cambridge, Mass., March 26, 1960.

Gluckauf, E. Proceedings Royal Society. A185, 98 (1946).

Holstein, T. Westinghouse Research Report 411-9-D.

Norton, F. J. Helium Diffusion Through Glass. Journal of The American Ceramic Society. V36N3, March 1953.

Nottingham, W. B. and Torney, F. L. Jr. A Detailed Examination of the Principles of Ion Gauge Calibration. American Vacuum Society, Seventh National Symposium. 
Rogers, W. ; Buritz, R. and Alpert, D. Diffusion Coefficient, Solubility, and Permeability for Helium in Glass. Journal of Applied Physics. V25, N7 July 1954 .

Von Amerongen, G. J. Permeability of Rubbers to Gasses. Journal of Applied Physics 17, pp $972-8519 \overline{46 .}$

Warren, B. E. and Biscoe, J. Fourier Analysis of X-Ray Patterns of Soda-Silica Glass. J. American Ceramic Society 21, 1938.

\section{General Reference Works}

Cumulative Book Index. The H. W. Wilson Company

The Engineering Index. Engineering Index, Inc. New York.

The International Dictionary of Physics and Electronics. D. Van Nostrand Company.

Unpublished Material

Catalano, S. J. Investigation of Helium Permeation into the 9.20.

Jordon, H. F. Helium Permeation of the Bendix Corporation KCD. 1960.

\section{Correspondence}

Sylvania Electric Products Inc. April 13, 1961. 


\section{APPENDIX A}

DERIVATION OF FICK'S EQUATION 
It is required that the Continuity Equation hold, or as it is sometimes stated, that mass be conserved (1). The Continuity Equation is developed below.

Consider an elemental parallelepiped volume with surface $\mathrm{X}$ in the $X$-plane, a surface $y$ in the $Y$-plane, and a surface $Z$ in the $Z$ plane: The storage of fluid due to flow into the volume through $\mathrm{X}$ is

$$
-\frac{\partial}{\partial x}\left(e V_{x}\right) d x d y d z
$$

through $y$ is

$$
-\frac{\partial}{\partial y}\left(e V_{y}\right) d x d y d z
$$

and for $Z$ is

$$
-\frac{\partial}{\partial z}\left(e V_{z}\right) d x d y d z
$$

where $\rho$ is the density and $V$ is velocity.

The total amount of fluid stored in the volume would then be the sum of the se storages or

$$
-\left[\frac{\partial}{\partial x}\left(e V_{x}\right)+\frac{\partial}{\partial y}\left(e V_{y}\right)+\frac{\partial}{\partial z}\left(e V_{z}\right)\right] d x d y d z
$$

and the rate of increase of mass of the parallelepiped is

$$
\frac{\partial e}{\partial t} d x d y d z
$$

The rate of increase of mass will equal the amount of fluid stored in the volume,

\section{Hill, 1958}

${ }^{1}$ A. B. Cambel and B. H. Jennings. Gas Dynamics, McGraw- 


$$
-\left[\frac{\partial}{\partial x}\left(e V_{x}\right)+\frac{\partial}{\partial y}\left(e V_{y}\right)+\frac{\partial}{\partial z}\left(e V_{z}\right)\right]=\frac{\partial e}{\partial t}
$$

or

$$
\operatorname{dive} V=-\frac{\partial e}{\partial t}
$$

For a steady flow with no increase in mass; $\frac{\partial E}{\partial E}=0$ and the continuity equation becomes $P \operatorname{div} \rho V=0$ or

$$
\operatorname{ediv} V+V \cdot \nabla_{e}=0
$$

and if the flow is incompressible, $e=k$, and $\operatorname{div} V=0$. Therefore there is no gain or loss of mass in the elemental volume and the fluid that enters the parallelepiped, under steady state conditions; will also leave the volume. Fick's Equation can now be developed (2).

Two assumptions are made relative to the material through which the gas is diffusing:

I. Permeability does not vary.

II. The material is an isotropic medium, or a medium whose structure and properties in the neighborhood of any point are the same relative to all directions through the point.

Because of the assumed symmetry, the current of gas flow at a point must be along the normal to the surface of constant concentration through the point and in the direction of decreasing or falling pressure.

The quantity (q) of gas which flows through a surface (S) in (t) seconds is for a medium of permeability $k$ and thickness $d$ :

$$
q=k \frac{\left(p_{1}-p\right)}{d} S t
$$

${ }^{2}$ Carslaw and Jaeger. Conduction of Heat in Solids, Clarendon Press, Oxford 1947. 
Consider two surfaces of different constant concentrations separated by an incremental distance $\Delta x$ as in Figure $I$.
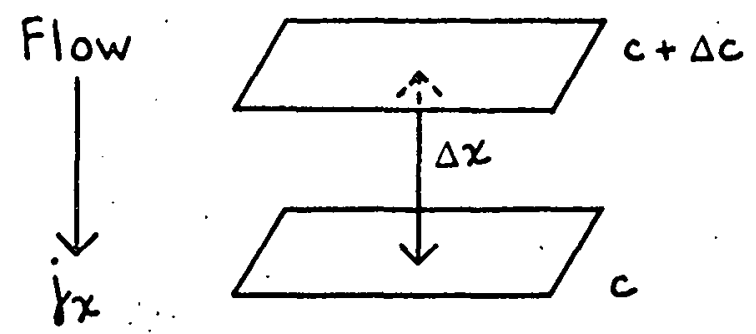

FIGURE I. FLOW BETWEEN TWO SURFACES

The rate of flow per unit time per unit area in the direction of $x$ increasing for a concentration $c$ is $j x=\frac{k[c-(c+\Delta c)]}{[(x+\Delta x)-x]}$

$$
\begin{gathered}
j_{x}=-\frac{k \Delta c}{\Delta x} \\
j_{x}=-k \frac{\partial c}{\partial x} \\
\text { Limit } \Delta x \rightarrow 0
\end{gathered}
$$

To reiterate; the rate at which gas particles cross from the inside to the outside of a surface of constant particle concentration or an isobaric surface, per unit time per unit area at a point, is equal to $-A \frac{\partial c}{\partial n}$ where $(k)$ is the diffusion factor and $\frac{\partial}{\partial n}$ denotes differentiation along the outward drawn normal to the surface.

Therefore to find the flow rate at a point $(P)$ across any surface for a three dimensional system with an isobaric plane through the point (P) and parallel to one of three mutually perpendicular planes, e.'g. the XY plane:

$$
\begin{aligned}
& j_{x}=j_{y}=0 \\
& j_{z}=-k \frac{\partial c}{\partial z}
\end{aligned}
$$


Similarly for the other two planes: $j_{x}=-k \frac{\partial c}{\partial x}$

or

$$
\begin{aligned}
& j y=-k \frac{\partial c}{\partial y} \\
& j=-k \nabla c
\end{aligned}
$$

The flow rate has been defined as has the concentration (c) at a point $P(x, y, z)=c(x, y, z, t)$.

Consider an elemental volume as in Figure II where the flow rate per unit time per unit area into the plane $A B C D$ is compared to the flow rate out of the plane $A^{\prime} B^{\prime} C^{\prime} D^{\prime}$.

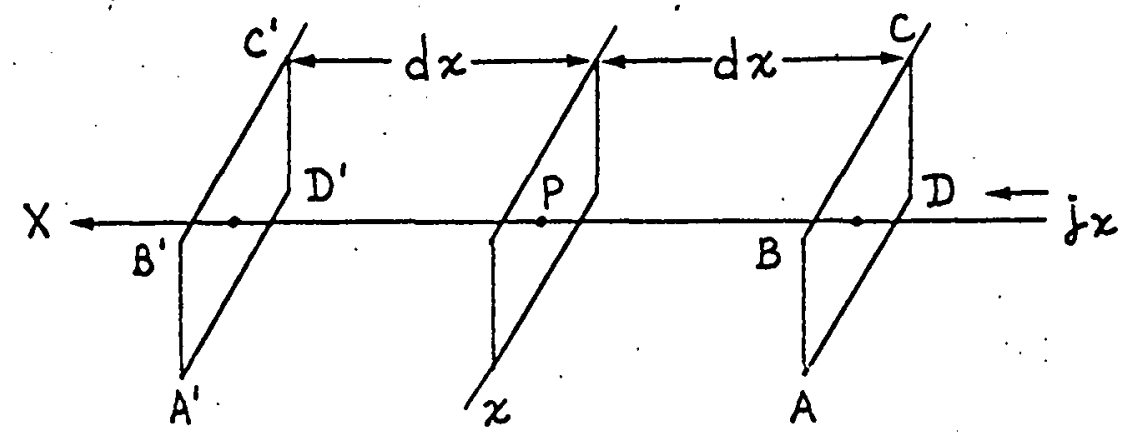

FIGURE II. FLOW THROUGH ELEMENTAL VOLUME

A plane with point $(P)$ is at $x$. The flow $j_{x}$ is normal to plane $A B C D$ and parallel to the $X$ axis. The area of plane $A B C D$ is $(2 \mathrm{~d} y)(2 \mathrm{~d} z)$ and is located at $(X-\Delta X)$.

The rate of particle flow into $A B C D$ is equal to the rate of flow at a point $P$ minus the change of flow rate over the surface at $A B C D$ times the area of the surface times the distance through which it flows, (dx):

$$
(2 d y)(2 d z)\left[j_{x}-\frac{d j x}{d[x-\Delta x]} d x\right]
$$

or

$$
4 d y d z\left[j_{x}-\frac{\partial j_{x}}{\partial x} d x\right]
$$


Similarly, the particle flow out of the face $A^{\prime} B^{\prime} C^{\prime} D^{\prime}$ is

$$
4 d y d z\left[j x+\frac{\partial j x}{\partial x} d x\right] \text {. }
$$

The rate of gain of flux entering $A B C D$ and leaving $A^{\prime} B^{\prime} C^{\prime} D^{\prime}$ is equation (15) - (16):

$$
-8 d x d y d z \frac{\partial j x}{\partial x}
$$

For the other planes of the elemental volume:

and

$$
-8 d x d y d z \frac{\partial j y}{\partial y}
$$

for the $Y$ and $Z$ directions respectively.

$$
-8 d x d y d z \frac{\partial j z}{\partial z}
$$

Since the elemental volume is gaining particle concentration at the rate

$$
8 d x d y d z \frac{1}{D} \frac{\partial C}{\partial t}
$$

and since the Continuity Equations hold it may be stated:

$-8 d x d y d z\left[\frac{\partial j x}{\partial x}+\frac{\partial j y}{\partial y}+\frac{\partial j z}{\partial z}\right]+8 d x d y d z \frac{1}{D} \frac{\partial c}{\partial t}=0$

and from (11), (12), (13),

$$
-\left[\frac{\partial\left(\frac{\partial c}{\partial x}\right)}{\partial x}+\frac{\partial\left(\frac{\partial c}{\partial y}\right)}{\partial y}+\frac{\partial\left(\frac{\partial c}{\partial z}\right)}{\partial z}\right]+\frac{1}{D} \frac{\partial c}{\partial t}=0
$$

For a homogeneous isotropic solid:

$$
\frac{1}{D} \frac{\partial c}{\partial t}=\frac{\partial^{2} c}{\partial x^{2}}+\frac{\partial^{2} c}{\partial y^{2}}+\frac{\partial^{2} c}{\partial x^{2}}
$$

or Fick's Law:

$$
\frac{\partial c}{\partial t}=D \nabla^{2} c
$$


Equation (22) states that the rate of diffusion of particles across a given area is proportional to the diffusion constant, D, and the concentration gradient. 
APPENDIX B

SOLUTION OF FICK'S EQUATION 
Under the conditions imposed in the experiment, the glass envelope of the vacuum tube was considered as the membrane of d thickness with volumes $V$ and $V_{1}$ on adjacent sides of the membrane. "The follow-. ing conditions were applied:

$$
\text { At. } \begin{array}{rlrlrl}
t & =0, c & =f(x) & \text { for } & 0<x<d \\
t & >0, c=c_{1} & \text { for } & x=0 \\
t & >0, c=c_{2} & \text { for } & x=d
\end{array}
$$

It is then necessary to solve the partial differential equation

$$
\frac{\partial c}{\partial t}=D \cdot \frac{\partial^{2} c}{\partial x^{2}}
$$

which is called Fick's Equation. One approach is by the separation of variables technique. (1). As a working hypothesis it is assumed that solutions of the gas concentration exist as products of a function of $X$ alone and a function of $t$ alone or

$$
c(x, t)=X(x) T(t)
$$

If this is the case, then partial differentiation of $c$ amounts to total differentiation of one or the other of the factors of $c$ and

$$
\begin{aligned}
& \frac{\partial c}{\partial t}=X T^{\prime} \\
& \frac{\partial^{2} c}{\partial x^{2}}=X " 1 T .
\end{aligned}
$$

By substitution into (1): $\mathrm{XT}^{\prime}=\mathrm{DTX} \mathrm{X}^{\prime \prime}$

and further

$$
\begin{gathered}
\frac{T^{\prime}}{T}=\frac{D X^{\prime \prime}}{X}=\alpha \\
T^{\prime}=T \propto D \text { if } \alpha>0 \text { or } \alpha=\lambda^{2}
\end{gathered}
$$

${ }^{1}$ C. R. Wylie, Jr. Advanced Engineering Mathematics. McGrawHill, 1951 
66

or, substituting

$$
T^{\prime}=T \lambda^{2} D
$$

and the solution is $T=A e^{\lambda^{2} t D}$

(9)

As stated in (9), as $t$ increases, the concentration would exceed the boundary condition. This is not an acceptable solution. However, if $\alpha=0 ; T^{\prime}=0$ and $T=$ constant

$$
X^{\prime \prime}=\alpha X=0
$$

and

$$
X=B x+C
$$

so

$$
c(x, t)=X T=A[B x+C]=B^{\prime} x+C^{\prime} .
$$

When

$$
\begin{aligned}
x=0 ; C^{\prime}=c_{1} \text { AND } x=d ; B^{\prime} d+c_{1} & =c_{2} \\
B^{\prime} & =\frac{c_{2}-c_{1}}{d} \\
c & =\left[\frac{c_{2}-c_{1}}{d}\right] x+c_{1}
\end{aligned}
$$

Therefore

Now if:

$$
\begin{aligned}
\alpha<0 \text { or } \alpha & =-\lambda^{2} \\
T^{\prime} & =-\lambda^{2} T D \\
T & =A e^{\lambda^{2} t D}
\end{aligned}
$$

and

$$
\begin{gathered}
X^{\prime \prime}=-\lambda^{2} X \\
X=B \cos \lambda x+C \sin \lambda x
\end{gathered}
$$

In this instance

$$
c(x, t)=A e^{-\lambda^{2} t D}(B \cos \lambda x+C \sin \lambda x)=e^{-\lambda^{2} t D}\left(B^{\prime} \cos \lambda x+C^{\prime} \sin \lambda x\right)
$$


67

When

$$
\begin{aligned}
& x=0 \\
& c=c_{1} \\
& t>0,
\end{aligned}
$$

Therefore $e^{-\lambda^{2} t D} B^{\prime} \cos \lambda x=c_{1}$

$$
B=\frac{c_{1}}{e^{-\lambda^{2} t D}} \cos \lambda x
$$

As $x=d$, there is already one solution so all others must vanish

$$
\begin{gathered}
c=e^{-\lambda^{2} t D}\left[\frac{C_{1}}{e^{-\lambda^{2} t D} \cos \lambda x}(\cos \lambda x)+C^{\prime} \sin \lambda x\right] \\
c(d, t)=c_{1} e^{-\lambda^{2} t D}+C^{\prime} \sin \lambda x\left(e^{-\lambda^{2} t D}\right)=0
\end{gathered}
$$

$-\lambda^{2} t D$

$\left[c_{1}+C^{\prime} \sin \lambda d\right]=0$ and $C^{\prime}=0$ is trivial

$C^{\prime} \sin \lambda d=0,-c_{1}=0$, then $\sin \lambda d=0$ and $\lambda n=\frac{n \pi}{d}$

where $n=1,2,3 \ldots \ldots$.

so $e^{-\lambda^{2} n t D}\left[c_{1} t C_{n}^{\prime} \sin \lambda x\right]=e^{\frac{-n^{2} \pi^{2} t D}{d^{2}}}\left[c_{1} t C_{n}^{\prime} \sin \frac{\pi n z}{d}\right]$

or

$$
c(x, t)=\left(c_{2}-c_{1}\right) \frac{x}{d}+c_{1}+\sum_{n=1}^{\infty} e^{\frac{-n^{2} \pi^{2} t D}{d^{2}}} C^{\prime} n \sin \frac{n \pi x}{d}
$$

Now

$$
\begin{aligned}
& c(x, t)=f(x) \text { when } t=0 \\
& f(x)=\left(c_{2}-c_{1}\right) \frac{x}{d}+c_{1}+\sum_{n=1}^{\infty} c_{n}^{\prime} \sin \frac{n \pi x}{d}+c_{1}
\end{aligned}
$$

The $\left(C^{\prime} n\right)^{\prime}$ are coefficients in the half-range sine expansion as

$Q$

$$
C_{n}^{\prime}=\frac{2}{p} \int_{0}^{p} f(t) \sin \frac{n \pi t}{p} d t
$$


where

$$
\begin{aligned}
f(t) & =\left[f(x)-\left(c_{2}-c_{1}\right) \frac{x}{d}-c_{1}\right] \\
p & =d_{;} t=x
\end{aligned}
$$

then $C_{n}^{1}=\frac{2}{d} \int_{0}^{d}\left\{f(x)-\left[\left(c_{2}-c_{1}\right) \frac{x}{d}+c_{1}\right]\right\} \sin \frac{n \pi x}{d} d x$

Expand and integrate:

$C_{n}^{\prime}=\frac{2}{d}\left\{\int_{0}^{d} f(x) \sin \frac{n \pi x}{d} d x+\left[\frac{C_{2} d}{n^{2} \pi^{2}} \sin \frac{n \pi x}{d}+\frac{C_{2} x}{n \pi} \cos \frac{n \pi x}{d}\right]_{0}^{d}+\right.$

$\left.\left[\frac{c_{1} d}{n^{2} \pi^{2}} \sin \frac{n \pi x}{d}-\frac{c_{1} x}{n \pi} \cos \frac{n \pi x}{d}\right]_{0}^{d}+\frac{c_{1} d}{n \pi} \cos n \pi-\frac{c_{1} d}{n \pi}\right\}$

Evaluate $C_{n}^{\prime}$ in (22) from the fact that for $n=1,2,3 \ldots \ldots \sin n \pi=0$

$$
C_{n}^{\prime}=\frac{2}{d} \int_{0}^{d} f(x) \sin \frac{n \pi x}{d} d x+\frac{2 c_{2}}{n \pi} \cos n \pi \frac{-2 c_{1}}{n \pi}
$$

Substituting in (18): The general solution for Fick's Equation with the as sumed boundary conditions is

$c(x, t)=\left(c_{2}-c_{1}\right) \frac{x}{d}+c_{1}+\sum_{n=1}^{\infty} e^{\frac{-n^{2} \pi^{2} t D}{d^{2}}} \sin \frac{n \pi x}{d}$

$\left(\frac{2}{d} \int_{0}^{d} f(x) \sin \frac{n \pi x}{d} d x\right)+\frac{2}{\pi} \sum_{n=1}^{\infty} c_{2} \frac{\cos n \pi-c_{1}}{n} \frac{\sin n \pi x}{d} e^{\frac{-n^{2} \pi^{2}+D}{d^{2}}}$ 
APPENDIX C

DATA OBTAINED FOR THE SECOND EXPERIMENT

$\rightarrow$ 
TABLE 1

\section{ION AND ELECTRON CURRENT READINGS TAKEN DURING EXPERIMENT WITH 6BN6's}

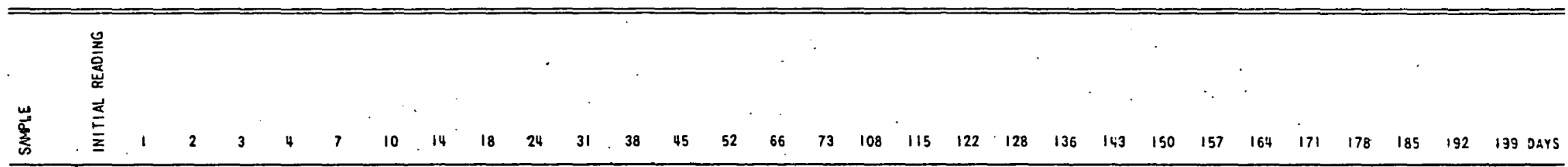

\begin{tabular}{llllllllllllllllllllll}
\hline & 0.90 & 0.80 & 0.61 & 0.68 & 0.69 & 0.72 & 0.86 & 0.85 & 0.74 & 0.81 & 0.87 & 0.75 & 0.64 & 1.09 & 0.83 & 0.55 & 0.63 & 0.61 & SAMPLE DESTROYED
\end{tabular}

A I $=\begin{array}{lllllllllllllllllllllllllllll} & 4.58 & 4.53 & 4.58 & 4.58 & 4.59 & 4.59 & 4.58 & 4.59 & 4.58 & 4.60 & 4.62 & 4.65 & 4.62 & 4.65 & 4.61 & 4.65 & 4.56\end{array}$

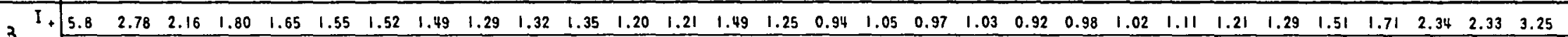

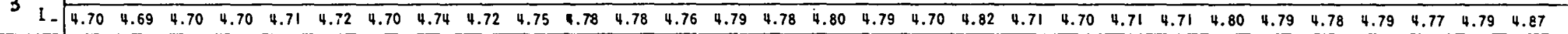

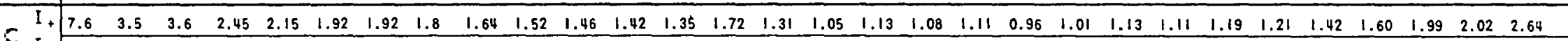

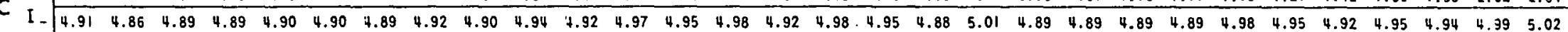

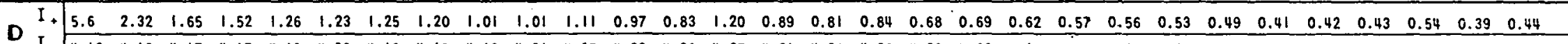

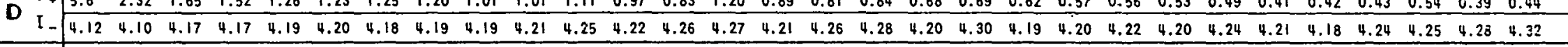

E I+ $\begin{array}{llllllllllllllllllllllllllllllllllllllllll} & 0.4 & 3.7 & 1.91 & 1.82 & 1.82 & 1.71 & 1.82 & 1.70 & 1.51 & 1.42 & 1.21 & 1.21 & 1.31 & 1.14 & 1.17 & 0.95 & 0.94 & 0.78 & 0.75 & 0.72 & 0.78 & 0.75 & 0.61 & 0.57 & 0.52 & 0.51 & 0.48 & 0.55 & 0.41 & 0.49\end{array}$

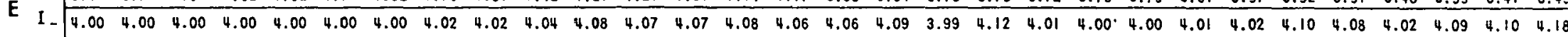

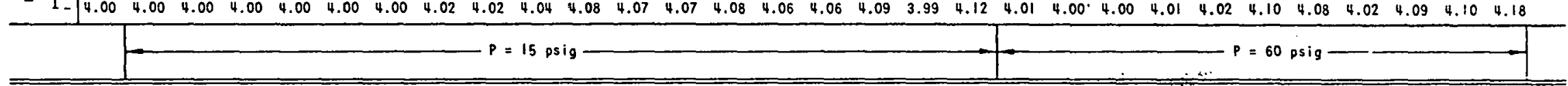

$$
\begin{aligned}
& \text { A, B, C IMMERSED IN PURE HELIIJM } \\
& \text { D,E CONTROL tUBES, AMBIENT ENU:KOSMEN: } \\
& \text { I. - ION CURREKT } \times 10-9 \text { aMPE?ES } \\
& 1 \text { - _ ELECRON CURRENT } \times \text { i0-3 AY?ERES } \\
& T=21^{\circ} \mathrm{C}
\end{aligned}
$$

